\title{
UN EJEMPLO DE POLÍTICAS DE IGUALDAD: LA ELIMINACIÓN DE LA DISCRIMINACIÓN POR RAZÓN DE SEXO EN LA SUCESIÓN DE LOS TÍTULOS NOBILIARIOS EN ESPAÑA
}

\author{
AN EXAMPLE OF EQUALITY POLICIES: THE ELIMINATION OF \\ DISCRIMINATION BASED ON SEX IN THE SUCCESSION OF NOBLE \\ TITLES IN SPAIN
}

Mercedes de Prada Rodríguez ${ }^{1}$

\section{ABSTRACT:}

THE EQUALITY BETWEEN WOMEN AND MEN AND THE ELIMINATION OF THE DIFFERENCES BETWEEN BOTH ARE AN AIM THAT MUST BE PART OF ALL THE POLICIES AND ACTIONS OF THE UNION AND OF HIS MEMBERS. ON THE BASE OF THE CONVENTION FOR THE ELIMINATION OF ALL THE FORMS OF DISCRIMINATION AGAINST THE WOMAN THE LAW 33/2006, OF OCTOBER ABOUT EQUALITY BETWEEN MAN AND WOMAN IN THE ORDER OF SUCCESSION OF THE PERTAINING TO NOBILITY TITLES. AS THE LITN INDICATES, NOTHING ALLOWS TO CONSIDER BEING ARBITRARY OR LACKING IN JUSTIFICATION ON THE INTENTION OF THE LEGISLATOR OF PROJECTING THIS FULL EQUALITY "ALSO ON THE MERELY REPRESENTATIVE AND SYMBOLIC FUNCTIONS, WHEN THESE ARE RECOGNIZED AND PROTECTED BY THE LAWS " AND OF EXTENDING THE ABOVE MENTIONED PROJECTION RETROACTIVELY, WITHOUT INFRINGING THE LIMITS IMPOSED BY THE CE, TO THE SITUATIONS THAT IT CONSIDERS NOT YET CONSOLIDATED.

LA IGUALDAD ENTRE MUJERES Y HOMBRES Y LA ELIMINACIÓN DE LAS DESIGUALDADES ENTRE UNAS Y OTROS SON UN OBJETIVO QUE DEBE INTEGRARSE EN TODAS LAS POLITICAS Y ACCIONES DE LA UNIÓN Y DE SUS MIEMBROS. SOBRE LA BASE DE LA CONVENCIÓN PARA LA ELIMINACIÓN DE TODAS LAS FORMAS DE DISCRIMINACIÓN CONTRA LA MUJER SE HA APROBADO LA LEY 33/2006, DE 30 DE OCTUBRE, DE 30 DE OCTUBRE, SOBRE IGUALDAD DEL HOMBRE Y LA MUJER EN EL ORDEN DE SUCESIÓN DE LOS TÍTULOS NOBILIARIOS. COMO SEÑALA LA LITN, NADA PERMITE CONSIDERAR ARBITRARIO O CARENTE DE JUSTIFICACIÓN EL PROPÓSITO DEL LEGISLADOR DE PROYECTAR ESTA PLENA IGUALDAD «TAMBIÉN SOBRE LAS FUNCIONES MERAMENTE REPRESENTATIVAS Y SIMBÓLICAS, CUANDO ÉSTAS SON RECONOCIDAS Y AMPARADAS POR LAS LEYES» Y DE

1 Doctora en Derecho. Profesora de Derecho Procesal. Centro Universitario Villanueva y Escuela de Práctica Jurídica. Universidad Complutense de Madrid. E-mail: mprada@ villanueva.edu.

REVISTA DO DIREITO UNISC, SANTA CRUZ DO SUL No $39 \mid$ p. 89 - 125 | JAN-JUL 2013 
EXTENDER DICHA PROYECCIÓN CON CARÁCTER RETROACTIVO, SIN INFRINGIR LOS LÍMITES IMPUESTOS POR LA CE, A LAS SITUACIONES QUE ESTIMA NO CONSOLIDADAS.

\section{PALABRAS CLAVE:}

TITLES OF NOBILITY ASPECTS, / ON GENDER EQUALITY IN NOBILITY SUCCESSIONS/ FOR THE ELIMINATION OF ALL THE FORMS OF DISCRIMINATION AGAINST THE WOMAN/EQUALITY.

TÍTULOS NOBILIARIOS, / IGUALDAD DE SEXOS EN LA SUCESIÓN NOBILIARIA/ ELIMINACIÓN DE TODAS LAS FORMAS DE DISCRIMINACIÓN/.

SUMARIO: I.- CONSIDERACIONES GENERALES.- I.- LOS TítUloS NOBILIARIOS: A. Concepto. B. Ámbito constitucional. C. Naturaleza: concesión administrativa y sucesión civil. II.- EN TORNO A LA IGUALDAD DEL HOMBRE Y LA MUJER EN LA SUCESIÓN A UN TÍTULO NOBILIARIO: DOCTRINA JURISPRUDENCIAL Y DEL CONSEJO DE EstADO. A. La doctrina del Tribunal Supremo; B. La doctrina del Tribunal Constitucional; C. El Consejo de Estado y el principio de varonía. III.- SOBRE LA IGUALDAD DEL HOMBRE Y LA MUJER EN EL ORDEN DE SUCESIÓN DE LOS TÍTULOS NOBILIARIOS: LEY 33/2006, DE 30 DE OCTUBRE.

\section{I.- CONSIDERACIONES GENERALES}

Como señala la Exposición de Motivos de LO 3/2007, de 22 de marzo para la igualdad efectiva de mujeres y hombres, la igualdad es un principio fundamental en la Unión Europea. Esta ley de carácter integral introduce la igualdad de trato y de oportunidades entre mujeres y hombres en todas las esferas de la vida, especialmente en las esferas política, civil, laboral, económica, social y cultural, y en todas las actuaciones de las Administraciones Públicas, respondiendo al principio de transversalidad de género. Desde la entrada en vigor del Tratado de Ámsterdam, el 1 de mayo de 1999, la igualdad entre mujeres y hombres y la eliminación de las desigualdades entre unas y otros son un objetivo que debe integrarse en todas las políticas y acciones de la Unión y de sus miembros. Para ello y dentro del marco constitucional era necesario una regulación legal dirigida a combatir todas las manifestaciones aún subsistentes de discriminación, 
directa o indirecta, por razón de sexo y a promover la igualdad real entre mujeres y hombres, con remoción de los obstáculos y estereotipos sociales que impiden alcanzarla. La Ley se refiere a las generalidades de las políticas públicas en España, tanto estatales como autonómicas y locales. Y lo hace al amparo de la atribución constitucional al Estado de la competencia para la regulación de las condiciones básicas que garanticen la igualdad de todos los españoles y las españolas en el ejercicio de los derechos constitucionales, aunque contiene una regulación más detallada en aquellos ámbitos de competencia, básica o legislativa plena, del Estado.

Sobre la base de la Convención para la eliminación de todas las formas de discriminación contra la mujer se ha aprobado la Ley 33/2006, de 30 de octubre, de 30 de octubre, sobre igualdad del hombre y la mujer en el orden de sucesión de los títulos nobiliarios. Como señala la LITN, nada permite considerar arbitrario o carente de justificación el propósito del legislador de proyectar esta plena igualdad «también sobre las funciones meramente representativas y simbólicas, cuando éstas son reconocidas y amparadas por las leyes» y de extender dicha proyección con carácter retroactivo, sin infringir los límites impuestos por la CE, a las situaciones que estima no consolidadas.

Todas estas cuestiones serán objeto de desarrollo en nuestro trabajo, pero antes de nada, debemos realizar una importante puntualización en esta materia: el Derecho nobiliario está regido por una normativa que tiene un origen histórico indudable y que conforma un ordenamiento jurídico de carácter especial, en la medida en que está regido por principios jurídicos que, en muchas ocasiones, divergen de los que inspiran otras ramas de nuestro Derecho.

\section{I.- UNA APROXIMACIÓN A LOS TÍTULOS NOBILIARIOS}

Son muchas las definiciones que se pueden dar de un título nobiliario en función de que se resalten unos $u$ otros aspectos, tal y como pone de relieve 
doctrina y jurisprudencia ${ }^{2}$. En una primera aproximación, podemos definir un título nobiliario como una distinción o nomen honoris otorgado por el Jefe del Estado a personas físicas como recompensa por méritos o servicios; distinción que tiene un carácter honorífico y que no está vinculada en la actualidad a ningún bien tangible ${ }^{3}$. Así entendido, el título nobiliario implica un derecho exclusivo y excluyente de usar y disfrutar social, pública y privadamente el nombre o calificativo del título con todas las prerrogativas legales y tradicionales inherentes a él.

Las características que se atribuyen a una merced nobiliaria se pueden sintetizar en que son: graciables; incesantes o permanentes; inalienables; perpetuos o imprescriptibles y vinculados (ASENJO, 1955); así como la máxima expresión del Derecho premial ${ }^{4}$.

2 Entre otros, Jiménez Asenjo, E., Régimen de los Títulos de Nobleza en España, América y Filipinas, Barcelona, 1955, pág. 44; VAllterra FERnÁndeZ, L., Derecho Nobiliario Español, Granada, 1995, pág. 23 y ss; TABoAda RocA, M., Estudios de Derecho Nobiliario, Tomos I y II, Madrid, 2001, pág. 32, así como también, LóPEZ VILAS, R., Régimen jurídico de los títulos nobiliarios (sucesiones y rehabilitaciones), Madrid, 1974, pág. 48. DE PRADA RodrígueZ, M., La tutela sustantiva y procesal de los títulos nobiliarios, Civitas, 2009, págs.101 y ss. Por otra parte, la definición que se ofrece en la STC 126/1997, de 3 de julio, es clarificadora en cuanto a su contenido como derecho honorífico: "un título nobiliario es -y no es más que eso- una preeminencia o prerrogativa de honor, y por eso se entiende nemine discrepante que su concesión corresponde al Rey como uno de esos honores a que se refiere el art. 62 f) CE. Pero en el uso del título (adquirido por sucesión directa o por vía sucesoria) se agota su contenido jurídico, y no es, como en el Antiguo Régimen, signo definitorio de un status o condición jurídica estamental privilegiada. Su esencia o consistencia se agota en su existencia".

${ }^{3}$ Etimológicamente "noble" deriva de la palabra latina nobilis o noscibilis, que significa conocido, digno de ser conocido o el que se da a conocer y de que con el término título, merced o dignidad nobiliaria se hace referencia a un honor, a un reconocimiento, a una recompensa, a una distinción, concedida por el Jefe del Estado que se transmite siguiendo un orden peculiar establecido en la Carta de fundación y sin vinculación en la actualidad a bienes materiales. Como afirma Jiménez AsEnjo, E., Régimen jurídico..., op. cit., pág. 45, socialmente representa una preeminencia personal; políticamente, una distinción o un honor; $y$, civilmente $\mathrm{o}$ jurídicamente, constituye una cosa o res, una creación intelectual del poder público: una res iuris, sin corporeidad tangible o manifiesta, en definitiva, una "idea pura, un ente jurídico".

${ }^{4}$ Los títulos nobiliarios constituyen una materia singular, caracterizada por lo que GUASP, J., y Aragoneses, P., Derecho Procesal Civil, Tomo II, Madrid, 2002, págs. 164-65, acertadamente define como "Derecho premial que junto con el Derecho penal constituye el anverso y el reverso de una misma figura". Esta singularidad se refleja en el uso que la Administración hace de su potestas para incentivar a sus ciudadanos a desarrollar conductas ejemplares, mediante el recurso a premios de muy variada índole. También GUASP, J., en el Prólogo a la obra Régimen jurídico de los Títulos de Nobleza, de JimÉnEZ AsEnjo, E., Régimen jurídico de los Títulos de Nobleza de España, América, Filipinas, Barcelona, 1955, pág. 9, afirma que "en un medio social tan inerte a los valores como lo es el de hoy, no cabe rehusar cualquier estímulo que permita reaccionar adecuadamente ante lo que es laudable y lo que es, por el contrario, digno de censura. No todo en esta tarea educativa ha de ser pena; algo tiene que haber de premio, siquiera nuestros avances en Derecho premial no están a la altura de lo que en Derecho penal se ha evolucionado". También, vid., Rubio Gordo, P., Derecho Premial, Madrid, 2006, pág. 23. 
Tal y como señala la jurisprudencia -que se erige en auténtica fuente del Derecho Nobiliario ${ }^{5}$ - el título, la merced concedida, es un bien inmaterial que constituye un nomen honoris ${ }^{6}$, es decir, una unidad indivisible que únicamente puede ser transmitida mortis causa y exclusivamente a una persona de entre todos los parientes del primer poseedor ${ }^{7}$.

\section{1. Ámbito constitucional}

La forma política del Estado Español es la Monarquía parlamentaria (art. 1.3 CE) y se proclama el principio de igualdad de todos los ciudadanos como valor superior del ordenamiento jurídico (art. $14 \mathrm{CE}$ ). Aunque en el texto constitucional se reconoce de forma expresa a los títulos nobiliarios referentes al Rey y a su familia, afirmando su carácter hereditario (art. $57 \mathrm{CE}$ ), respecto a la subsistencia de los títulos nobiliarios en general, se guardó un expresivo silencio. Sin embargo, y por disposición expresa, se admitió la posibilidad que se siguieran concediendo honores y distinciones como una de las facultades o funciones del Rey recogidas en el art. 62 f) CE, siempre con arreglo a las leyes ${ }^{8}$.

${ }^{5}$ Señala GarCía TORRES, J., "Non sint: la Constitución Española y las sucesiones nobiliarias mortiscausa: examen crítico de la argumentación constitucional contenida en la sentencia de la Sala Primera del Tribunal Supremo de 28 de abril de 1989", Revista Española de Derecho Constitucional (mayo-agosto 1990), Madrid, 1990, p.257, "que en Derecho Nobiliario español hay un Common Law judicial frente a un disperso elenco y residual Statute Law, centrado en procedimientos administrativos".

${ }^{6}$ La STS 10 de marzo de 2004 (RJ 173/2004) mantiene que "los títulos de nobleza no poseen una proyección general definitoria de un estatus, sino ante un simple nomen honoris que implica referencia a la historia en cuanto símbolo y no posee otro valor que el puramente social que en cada momento quiera otorgársele".

${ }^{7}$ Vid., STC 126/1997, de 3 de julio. Asimismo, el Tribunal Supremo reitera en STS de 11 de mayo de 2000 (RJ 200013408) que "se trata de una materia que no admite la cotitularidad en sus diversas formas, ya que la merced nobiliaria sólo puede ser ostentada por una única persona".

${ }^{8}$ En las SSTS de 25 de febrero de 1983 (RJ 1983/1073), de 16 de junio de 1984, de 21 de marzo de 1985 (RJ 1985/1194) y de 27 de julio de 1987 (RJ 1987/5877) se afirma de forma unánime que la concesión de honores y distinciones con arreglo a las leyes es exclusivamente una potestad regia. Por otra parte, la STC 126/1997, de 3 de julio, señala que los títulos nobiliarios han subsistido en la sociedad burguesa y en el régimen constitucional, sin duda, por su directa vinculación con la Corona como fons nobilitatis; aunque, como bien indica la STC 27/1982, de 24 de mayo, los títulos nobiliarios sólo han permanecido "como instituciones residuales de la sociedad anterior que se incrustan en la nueva y logran persistir en ella, bien es cierto que con un contenido jurídico y una función social enteramente otras y menores que las que tuvieron antes". 
Es cierto que los títulos nobiliarios no se citan expresamente en la $\mathrm{CE}^{9}$, pero si el objetivo hubiera sido suprimirlos, lógicamente se habría declarado explícitamente en una norma ad hoc, tal y como recogieron textos constitucionales anteriores y los ordenamientos de otros países de nuestro entorno $^{10}$. Así, la STC 1982l27, de 24 de mayo, señala que "el legislador constituyente pudo prohibir la concesión de nuevos títulos, al menos de títulos hereditarios, e incluso pudo prohibir o mitigar la subsistencia de los antiguos. Pero lo cierto es que, aunque la Constitución no los menciona, los títulos nobiliarios existen en sus dos formas: los antiguos y los de nueva creación". En efecto, el poseer un título nobiliario, es un hecho admitido por el ordenamiento jurídico actual, que ampara constitucionalmente su concesión por el Rey a cualquier español como acto de gracia o merced en cuanto a la decisión última, pero en todo caso, "con arreglo a las leyes"11. En consecuencia, si se admite la fundamentación constitucional de los títulos no es posible afirmar que determinados elementos de dicha institución sean inconstitucionales, siempre y cuando sus efectos queden circunscritos al ámbito de la propia institución nobiliaria y no dañen otros derechos constitucionalmente amparados ${ }^{12}$.

El Tribunal Constitucional afirma que de este silencio constitucional se derivan dos consecuencias: en primer lugar, que esta referencia de la CE es tan amplia que permite al legislador un margen para decidir sobre el tratamiento de estas dignidades; $y$ en segundo término, que el silencio de la CE

${ }^{9}$ Entrena Cuesta, R., Comentarios a la Constitución (Coord. Garrido Falla, F.), Madrid, 2001, pág. 1081, afirma que este precepto tiene sólo el interés de dejar plasmado constitucionalmente el reconocimiento del Derecho nobiliario, matizando que la potestad regia estará condicionada por las disposiciones de rango legal y reglamentario que conforman el ordenamiento jurídico nobiliario. También, señala GARCíA DE ENTERRÍA, E., en el prólogo a la obra de HERNÁNDEZGil Álvarez Cienfuegos, A., La preferencia del varón en la sucesión nobiliaria después de la Constitución, Madrid, 1992, págs. 18-19, que aún reconociendo que esta institución no tiene una gran trascendencia social, está "viva" y por ello "la Constitución la ha querido mantener". En sentido análogo, vid. Arévalo Gutiérrez, A., "La mujer en el Derecho nobiliario: la mujer en la sucesión a la Corona”, op. cit., pág. 348. Vid. también R DE EsPONA, R., "El erróneo concepto de "título nobiliario", AFDUDC, 12, 2008, págs. 247-268.

10 En Portugal, Francia, Alemania e Italia fueron suprimidos los títulos de nobleza pero la realidad es que, en la actualidad, se tolera su uso en la vida social. En el Reino Unido están oficialmente reconocidos y, además, llevan aparejados importantes privilegios.

11 La STC desestimó el recurso de amparo que trataba de dilucidar si el hecho diferencial admitido como condición para suceder "casar con persona noble" era discriminatorio. Cfr. TABOADA RocA, M., "La Constitución Española y la guerra de sucesiones en las mercedes nobiliarias", Revista Tapia, 1989. Vid. Rodríguez Zapata PÉrez, J., Compendio de Derecho Nobiliario, op. cit., págs. 17-55.

12 Cfr. Dictamen del Consejo de Estado 1591/91.

REVISTA DO DIREITO UNISC, SANTA CRUZ DO SUL

No $39 \mid$ p. 89 - 125| JAN-JUL 2013 
no impide que se pueda argumentar la incompatibilidad de las mercedes nobiliarias perpetuas o de algún extremo de su régimen tradicional con la norma suprema ${ }^{13}$. Sin duda, es evidente que la CE reconoce la existencia del Derecho premial en la concesión de recompensas que llevan aparejadas preeminencias sociales otorgadas por el poder público en atención a los méritos y servicios prestados ${ }^{14}$. De esta forma, el interés que se deduce del art. $62 \mathrm{f})$ es dejar plasmado el reconocimiento del Derecho nobiliario ${ }^{15}$; y el de los arts. 56.2 y $57.2 \mathrm{CE}$, el de la existencia de la institución nobiliaria. Si bien, las Cortes no están supeditadas a ninguna directriz constitucional para diseñar la legislación nobiliaria.

De todo lo anterior se desprende que el poseer un título nobiliario es un hecho admitido y reconocido por nuestro ordenamiento jurídico constitucional; pero sin más trascendencia que la de permanecer en una esfera personal y honorífica, que sólo recoge el derecho a su uso y disfrute. En este contexto, podemos afirmar que la posesión de un título constituye una preeminencia o prerrogativa de honor que no entraña privilegio alguno o especial ventaja

13 Cfr. STC 1995\114, de 6 de julio.

14 Para López-Nieto y Mallo, F., Honores y Protocolo, Madrid, 1985, págs. 14-16, las normas que regulan la concesión de las distinciones honoríficas podrían formar parte de la normativa del Derecho administrativo recibiendo la denominación de Derecho premial. Y, según la normativa vigente, las únicas recompensas que conllevan una cierta distinción personal y perdurable son la concesión de títulos nobiliarios o el ingreso en las Órdenes que comportan el uso de una condecoración. Definen Ceballos-Escalera, A. De, y García Mercadel, F., Las Órdenes y condecoraciones civiles del Reino de España, Madrid, 2001, pág. 49, las condecoraciones como "una señal de honor, concedida por la Corona -el Estado- a título vitalicio, a aquella persona que la ha merecido por una acción o serie de acciones relevantes y específicas. Y, en cuanto a las Órdenes militares, podemos afirmar que son corporaciones que funcionan de hecho como asociaciones privadas, como Órdenes nobiliarias civiles cuyo carácter jurídico no está definido. Por otro lado, las Maestranzas de caballería son corporaciones nobiliarias de carácter jurídicoprivado. En los mismos términos, Mozo Seonne, A., Derecho Nobiliario, Madrid, 2005, págs. 45-80, hace una especial referencia a las Órdenes Militares de Caballería. En sentido análogo, Rubio Gordo, P., Derecho Premial, Madrid, 2006, pág. 31, considera que el Derecho premial está constituido por la normativa nobiliaria histórica y la legislación referente a las Órdenes y condecoraciones, civiles y militares y toda la relacionada con el protocolo oficial, tratamientos y precedencias. Vid. también, PÉREZ DE ARMiñán, A., Compendio de Derecho Nobiliario, Madrid, 2002, págs. 145-165.

15 En el mismo sentido, el Voto particular del Magistrado Cruz Villalón en la STC 18 de julio de 1997: "los títulos nobiliarios son una institución viva, por no decir pujante, que encuentra, en principio, su asiento, como siempre se ha entendido, en una de las facultades que al rey le corresponden, la de conceder honores y distinciones con arreglo a las leyes". Esta facultad está regulada en los RRDD 602/1988, 569/1981, 22/1988, art. 43 del RDLEG 1/1993 y RD 1879/1994. 
política, ni lesiona principios o derechos constitucionales ${ }^{16}$. Para el Tribunal Constitucional, el título nobiliario es un símbolo, un nomen honoris que se agota en el derecho a adquirirlo, usarlo y protegerlo frente a terceros, de modo semejante a lo que sucede con el derecho al nombre ${ }^{17}$.

Este reconocimiento normativo y jurisprudencial de la existencia en nuestro país de los títulos nobiliarios ha supuesto la constitucionalización de un derecho de origen histórico (CUESTA, 2001) y ha permitido resolver las colisiones jurídicas que en diferentes momentos se han suscitado con respecto a ciertos aspectos de su constitucionalidad, entre los que debemos resaltar los criterios que rigen la sucesión, dado su carácter excepcional ${ }^{18}$.

\section{Naturaleza: concesión administrativa y sucesión civil}

En cuanto a su naturaleza, los títulos nobiliarios participan de una doble naturaleza jurídica: administrativa y civil. Por un lado, son mercedes concedidas por el Monarca y su condición está supeditada a la expedición de una Carta de concesión o sucesión ${ }^{19}$, originándose una relación jurídica administrativa entre el particular favorecido por la merced y la Administración.

16 Pemán Medina, P., "La sucesión a la Corona y su repercusión en la sucesión a los títulos nobiliarios", La reforma constitucional, Madrid, 2005, pág. 470, manifiesta que los títulos de nobleza "no tienen más sentido que el de un legado cultural e histórico que la Ley protege como un bien social".

17 Los títulos nobiliarios no suponen privilegio alguno en nuestra sociedad y no atribuyen derechos o ventajas, sino tan sólo el derecho de poder "usar" el título. Así es como lo entiende el TC en la STC 1982 227, de 24 de mayo. Reiterado en la STS 10 de marzo de 2004 (RJ 173/2004) al decir que un título es simplemente un nomen honoris, un símbolo que no posee otro valor que el puramente social que en cada momento quiera otorgársele.

18 La Guía Oficial de Grandezas y Títulos del Reino recoge en cifras la situación de la Nobleza titulada hasta el 31 de diciembre de 2004. Así, hasta ese momento había 2.789 Títulos llevados por 2.199 personas. El total de Títulos de la Casa Real eran 4; de Títulos del Reino: 2.745; de Títulos extranjeros: 40; de Grandes de España: 408 y sin Grandeza: 2.337. Los datos más recientes nos los proporciona amablemente SALAZAR ACHA, J. DE, La Concesión de Títulos Nobiliarios, capítulo VII del libro, El Rey, (Coord. Escudero LÓPEZ, J.A.), pág. 12, Madrid. El autor nos indica que en el momento presente, existen reconocidos un total de 2.738 títulos que pueden desglosarse así: 153 duques; 1.349 marqueses; 922 condes; 145 vizcondes; 162 barones; y 7 señores. De todos ellos, están en posesión de la Grandeza de España un total de 378 títulos.

18 No en vano, la construcción del sistema nobiliario ha sido tarea jurisprudencial, por lo que nos ha sido de gran utilidad en nuestro estudio la recopilación jurisprudencial que realiza BARREDO DE ValenZuela, A., Treinta años de jurisprudencia nobiliaria, Madrid, 1979.

19 Un ejemplo de concesión es el del Real Decreto de 24 de marzo de 1890 por el que se concedió el título de Marqués de... a favor de doña. (...) "para si, sus hijos y sucesores legítimos"; y con fecha de 23 de julio de 1890 se expidió Real Despacho "para vuestros hijos y sucesores legítimos, varones y hembras, por el orden de sucesión regular cada uno en su respectivo tiempo y lugar perpetuamente"

REVISTA DO DIREITO UNISC, SANTA CRUZ DO SUL

No $39 \mid$ p. 89 - 125 | JAN-JUL 2013 
Por otro lado, el Derecho sustantivo regulador de la sucesión en los títulos nobiliarios -que es un tipo de sucesión excepcional o extraordinaria en favor de los de los descendientes del fundador-, es el Derecho civil aplicable entre personas particulares, unidas por unas relaciones privadas de las que la Administración es completamente ajena y cuyo conocimiento, en caso de pleito, corresponde a los tribunales del orden civil de la jurisdicción ordinaria ${ }^{20}$.

La naturaleza del título es meramente honorífica y su finalidad última es mantener vivo el recuerdo histórico al que se debe su otorgamiento. Las dignidades nobiliarias como verdaderas vinculaciones, son bienes a los que se les ha sustraído una de las facultades de dominio: la facultad de disposición. En consecuencia, al ser indisponibles, sólo se transmiten por fallecimiento del titular a través de un modo excepcional de sucesión, ni testada ni intestada, que se rige por el orden fijado en la Real Carta de concesión, ley del título ${ }^{21}$. El título fija de acuerdo con la ley sucesoria establecida que los poseedores no suceden al inmediato tenedor sino al primer fundador "por aplicación del derecho de sangre, no por aplicación de las normas de la sucesión", de modo que la muerte es la causa del llamamiento a una única sucesión pero con múltiples delaciones ${ }^{22}$.

Esta naturaleza mixta de la materia nobiliaria hace posible que, en relación a un mismo título, puedan sucederse dos procedimientos: primero, un procedimiento administrativo, que culmina con la Orden de expedición y la Carta de sucesión; y, después, un eventual proceso civil promovido por quien se considera "tercero de mejor derecho". Y es que si alguna persona se estima preterida por creerse con un mejor derecho a la sucesión, puede "ejercitarlo en juicio [civil] ordinario"23 (RD 27 de mayo de 1912), toda vez que la adjudicación

20 Así lo refleja el Dictamen del Consejo de Estado de 21 de noviembre de 1996, (3.275/1996). Del mismo modo el Dictamen del Consejo de Estado de 1 de marzo de 1952, afirma que “... la sucesión de una dignidad nobiliaria vacante debe ser deferida en vía administrativa, teniendo en cuenta la proximidad del parentesco con el último poseedor, sin entrar a discernir el mejor derecho de tercero respecto al que este último poseedor pueda ostentar, y sin perjuicio, desde luego, de que ese mejor derecho se haga valer más tarde por los interesados en la vía judicial”. Y, en sentido análogo, el Dictamen del Consejo de Estado 3.275/96.

21 La STS de 30 de julio de 1998 (RJ 1998/6928) resalta con claridad el carácter excepcional de la sucesión nobiliaria respecto de la sucesión ordinaria.

22 En este sentido, la STS de 13 de octubre de 1993 (RJ 7512\1993).

23 El art. 249.1 LEC, señala que "Se decidirán en juicio ordinario, cualquiera que sea su cuantía: $1^{\circ}$ Las demandas relativas a derechos honoríficos de las personas". El legislador ha considerado 
administrativa del título se entiende, en todo caso, "sin perjuicio de lo que los tribunales de justicia pudieran decidir, si se sometiera a ellos el asunto por cualquiera de las partes interesadas" (art. 6 RD 27 de mayo de 1912). En relación con el mejor derecho al título ejercitado en un juicio civil ordinario, la Administración se encuentra vinculada por la declaración judicial del mejor derecho, debe acatarla y respetarla y en el eventual procedimiento de sucesión habrá de hacer "lo que en Derecho proceda" 24.

Conviene, en este punto, añadir que los factores que tradicionalmente se han respetado para identificar a la persona que ostenta mejor derecho a una merced han sido la primogenitura o mayor edad, la masculinidad o varonía y la representación. Admitida la pervivencia de los títulos nobiliarios tras la entrada en vigor de la Constitución de 1978, surgió entonces la polémica acerca de si estos criterios sucesorios respetaban el canon constitucional de igualdad o si, por el contrario, resultaban ser discriminatorios y, por tanto, inconstitucionales (art. $14 \mathrm{CE}$ ). Al respecto, la jurisprudencia señaló de forma reiterada que tanto la primogenitura como la representación reunían los requisitos de necesidad y de objetividad indispensables para no ser considerados como discriminatorios. Sin embargo, en cuanto al principio de varonía, la polémica fue objeto de múltiples resoluciones judiciales y del Consejo de Estado, hasta ser definitivamente resuelta a través de la Ley 33/2006, de igualdad en la sucesión

que el Derecho nobiliario no necesita de una tutela jurisdiccional diferenciada: es un proceso que, sin más, se tramita por el procedimiento del juicio ordinario regulado en los arts. 399 y ss.

24 Cfr. Dictamen del Consejo de Estado 2414/2010. "Un examen de las sentencias dictadas en los últimos años por la Sala Tercera del Tribunal Supremo pone, efectivamente, de relieve cómo la jurisdicción Contencioso-Administrativa se limita a conocer de la legalidad de la actuación administrativa en expedientes de sucesión o de rehabilitación cuando se discute la legitimación de las partes, la procedencia de iniciar un expediente o la falta de requisitos o presupuestos que determinan la inadmisibilidad, la finalización, el archivo o sobreseimiento del expediente, pero no los criterios materiales en virtud de los cuales debe decidirse la sucesión. La preferencia por razón de sexo puede plantearse como cuestión de trámite al decidir sobre tales aspectos procedimentales, pero la decisión definitiva sobre la misma no corresponde a la jurisdicción Contencioso-Administrativa. La Sala Tercera, además, declara constantemente que «no hay derechos subjetivos a la concesión de las mercedes nobiliarias» (STS, Sala Tercera, de 17 de octubre de 1998 [ RJ 1998, 8841]), sino que su otorgamiento o reconocimiento constituye una prerrogativa real que se ejercita sin perjuicio de tercero de mejor derecho, salvedad que impone a quien alega la concurrencia de esta circunstancia en su favor la interposición ante el orden jurisdiccional civil de la correspondiente demanda. En fin, la falta de consolidación de la determinación del mejor derecho a ostentar el título que puede predicarse de la pendencia de un expediente administrativo concurre con igual o mayor intensidad cuando la incertidumbre deriva de la pendencia de una demanda civil sobre reclamación del mejor derecho a suceder". 
a los títulos nobiliarios. Al estudio de la doctrina emanada de esas resoluciones y de la mencionada Ley 33/2006 dedicamos el presente trabajo.

\section{III.- EN TORNO A LA IGUALDAD DEL HOMBRE Y LA MUJER EN LA SUCESIÓN A UN TÍTULO NOBILIARIO: DOCTRINA JURISPRUDENCIAL Y DEL CONSEJO DE ESTADO.}

\section{A. La doctrina del Tribunal Supremo}

Desde que en 1948 se restablece la legislación nobiliaria tradicional, el Tribunal Supremo ha seguido un criterio uniforme aplicando el Derecho histórico recogido en las Partidas, en las Leyes de Toro y en la Novísima Recopilación ${ }^{25}$.

Estos criterios históricos que establecen las normas sobre sucesión nobiliaria tienen su fundamentación en la naturaleza indivisible y extrapatrimonial de los títulos que determina que no admitan cotitularidad ${ }^{26}$ y que, además, obliga a respetar ciertos elementos objetivos y necesarios, llamados criterios preferentes de selección o exclusión. Estos criterios permiten decidir quién es, de los llamados a heredar, el que posee un mejor derecho genealógico. Ahora bien, es necesario distinguir cuáles son los mecanismos que determinarán el orden en los diferentes tipos de sucesión. Así, cuando se trate de una sucesión irregular los criterios nobiliarios se hallarán recogidos en la Real Carta de creación o concesión. Por el contrario, cuando la sucesión sea regular se seguirá el orden tradicional previsto para esta materia en la regulación histórica que establecía como principios de selección hereditarios, hasta la entrada en vigor de la Ley 30/2006, los criterios de preferencia de la mejor línea, el mejor grado, el varón sobre la mujer y la mayor edad.

De entre estos factores, sin duda el más polémico, hasta tiempos recientes, ha sido el principio de varonía o masculinidad. La histórica desigualdad entre sexos fue establecida en las Partidas $(2,15,2)$ y consolidada a lo largo del tiempo en armonía con una época y una sociedad caracterizada

25 Vid., De Prada Rodríguez, M., La tutela sustantiva y procesal de los títulos nobiliarios, págs. 166 y ss.

26 En este sentido, las SSTS de 26 de marzo de 1996 y de 11 de mayo de 2001, afirman que "la dignidad no tolera escisiones ni fragmentaciones y la vinculación es a perpetuidad".

REVISTA DO DIREITO UNISC, SANTA CRUZ DO SUL

No $39 \mid$ p. 89 - 125 | JAN-JUL 2013 
por los privilegios. El fundamento de esta desigualdad de la condición de la mujer fue motivada por su incapacidad para transmitir el linaje en condiciones de igualdad con el varón y su inferioridad en todos los órdenes ${ }^{27}$. Y, que con el transcurso del tiempo fue un criterio más incluido en la originaria redacción del CC.

En efecto, este secular principio sucesorio de preferencia, en igualdad de grado, del varón a la mujer ha pervivido hasta nuestros días siendo objeto de una significativa controversia desde la promulgación de la Constitución. Tras la proclamación en 1978 del principio de igualdad de todos los españoles ante la ley, "sin que pueda prevalecer discriminación alguna por razón de nacimiento, raza, sexo, religión, opinión o cualquier otra condición o circunstancia" consagrado en el art. $14 \mathrm{CE}$, la doctrina no ha sido indiferente respecto de su aplicación en relación con las reglas de la sucesión nobiliaria.

Pues bien, estos criterios de selección o preferencia en la sucesión nobiliaria sufrieron un cambio sustancial a raíz de tres sentencias del Tribunal Supremo. Nuestro Alto Tribunal afirmó que la preferencia del varón sobre la mujer en las sucesiones de títulos nobiliarios era contraria al principio de igualdad consagrado en la Constitución ${ }^{28}$. De esta doctrina nos interesa destacar los siguientes puntos:

$\left.1^{\circ}\right)$ La preferencia del varón sobre la mujer en las sucesiones nobiliarias se considera discriminatoria y, en consecuencia, abrogada por inconstitucionalidad sobrevenida con referencia a las sucesiones producidas a partir de la promulgación y vigencia de la Constitución; sin que a tal

27 Son tres las características se consideraban propias del sexo femenino: imbecillitas (inferioridad psicológica), fragilitas (debilidad e inferioridad física) y levitas animi (frivolidad).

28 Vid., SSTS de 7 de julio de 1986 (RJ 1986/4414), de 20 de junio (RJ 1987/4540) y de 27 de julio de 1987 (RJ 1987/5877). Las SSTS de 7 de diciembre de 1988 (RJ 198819324) y de 28 de abril 1989 denunciaron la inaplicación de la Convención de Nueva York de 18 de diciembre de 1979, ratificada por España el 16 de diciembre de 1983, consideró discriminatorio el principio de masculinidad y estimó su derogación por inconstitucionalidad sobrevenida, pero que solamente afectaba a las sucesiones en títulos nobiliarios producidos a partir de la promulgación y vigencia de la Constitución Española. Doctrina que siguen las SSTS de 22 de marzo de 1991 (199119809) y de 24 de enero de 1995, pero sin que pueda tener efecto retroactivo dicho efecto derogatorio. También, las SSTS de 21 de diciembre de 1989 (RJ 1989\8861), de 3 de enero de 1990 (RJ 199013), de 12 de diciembre de 1990 (RJ 1990/9997) y de 22 de marzo de 1991 en la que se cita las STC 1981\4, de 2 de febrero y STC 1983\8, 18 de febrero, en el sentido de que la eficacia trascendente del valor de igualdad que consagra el art. $14 \mathrm{CE}$ determina que toda situación de desigualdad, con origen en una circunstancia personal o social, deviene incompatible con el orden de valores proclamados por la $\mathrm{CE}$. 
abrogación puedan atribuírsele efectos retroactivos referidos a transmisiones y sucesiones operadas antes de dicha fecha.

$\left.2^{\circ}\right)$ La desigualdad que significa el principio de masculinidad deriva directamente de la Ley, por lo que no se trata de una simple desigualdad de hecho, sino de derecho. Lo característico en esta materia es la naturaleza indivisible del título que se hereda. Es necesario respetar determinados criterios objetivos necesarios de selección, que permiten decidir, en cada caso concreto, qué persona ostenta el preferente y mejor derecho genealógico a una dignidad. Ahora bien, estos criterios selectivos serán admisibles sólo en la medida en que no se equiparen con la acepción del término "discriminación", como equivalente a dar trato de inferioridad a la mujer por el mero e inevitable hecho de serlo, anteponiéndole, siempre e invariablemente, la condición de varón.

$3^{\circ}$ ) La Convención de Nueva York de 18 de diciembre de 1979, ratificada por España el 16 de diciembre de 1983, sobre "eliminación de todas las formas de discriminación de la mujer" fue suscrita por España -con la única salvedad expresa de "las disposiciones constitucionales en materia de sucesión a la Corona española"- y forma parte del ordenamiento jurídico interno en virtud de lo dispuesto en los artículos 96.1 CE y 1.5 CC dado su carácter de Derecho público constitucional y por ser ambos distintos en su origen y regulación legal $^{29}$. De este modo, se establece que la prohibición de discriminar a la mujer rige en todas aquellas materias sometidas al ordenamiento jurídico.

$\left.4^{\circ}\right) \mathrm{Y}$, por último, una cosa es la materia relativa a la sucesión a la Corona y otra, muy distinta, la sucesión de los títulos de nobleza ${ }^{30}$. La STS de 18 de abril de 1995 (RJ 1995/3421) declara que no cabe confundir ambas sucesiones fundándose en el carácter de Derecho público constitucional de la

29 Según el art. 96.1 CE "Los Tratados internacionales válidamente celebrados, una vez publicados en España, ganarán parte del ordenamiento interno" y "las normas jurídicas contenidas en los Tratados internacionales no serán de aplicación directa en España, en tanto no hayan pasado a formar parte del ordenamiento jurídico interno mediante su publicación íntegra en el BOE". Cfr. SSTS de 20 de junio (RJ 1987/4540), 27 de julio de 1987 (RJ 1987/5877) y de 28 de abril de 1989 (RJ 1989/9886).

30 SSTS de 20 de junio de 1987 (RJ 1987/4540), de 27 de julio de 1987 (RJ 1987/5877) y de 28 de abril de 1989 (RJ 1989/9886).

REVISTA DO DIREITO UNISC, SANTA CRUZ DO SUL

$\mathrm{N}^{\circ} 39 \mid$ p. 89 - 125| JAN-JUL 2013 
sucesión a la Corona que aparece específicamente regulada y diseñada en el artículo $57 \mathrm{CE}$.

A partir de ese momento la postura del Tribunal es clara: se entiende derogada la normativa histórica que recogía la preferencia del varón en la sucesión, y que, de modo supletorio, a falta de voluntad precisa del fundador, se aplicaba para determinar el orden sucesorio. El Tribunal Supremo aplica el principio de jerarquía normativa contenido en la Disposición Derogatoria Tercera de la CE, que declara derogadas todas las disposiciones que se opongan a lo establecido en ella ${ }^{31}$. Y entiende que este principio de preferencia del varón no cumple con los requisitos de objetividad y necesidad establecidos por la jurisprudencia constitucional ${ }^{32}$.

$\mathrm{Si}$ bien, esta derogación del principio de masculinidad tiene una importante limitación: sólo se referirá a las sucesiones que sigan un orden regular, no afectando en ningún caso a las sucesiones irregulares, en las que la voluntad del fundador es autónoma y puede disponer del título con absoluta libertad ${ }^{33}$.

Esta doctrina fue recogida en la Sentencia de 28 de abril de 1989 (RJ 1989/9886) al estimar la derogación por inconstitucionalidad sobrevenida del principio de masculinidad, a excepción de la sucesión de la Corona ${ }^{34}$. En ella, el Alto Tribunal proclama, como ratio decidendi del recurso y de la cuestión de fondo planteada, que, en la sucesión de títulos nobiliarios, el principio de

31 Vid. Cervilla Garzón, M.D. "De nuevo sobre la sucesión en los títulos nobiliarios (¿El punto y final a una absurda polémica?), Revista jurídica del Notariado, 59, julio-septiembre, 2006, pág. 202, subraya que en ese momento "se oyeron opiniones contrarias o "escandalizadas" por alterar un orden y una materia tradicionalmente consagrada bajo principios discriminatorios (...)".

32 Cfr. Autos del Tribunal Supremo de 1 de junio de 1999 (RJ 1999/3482) y de 8 de junio de 1999 (RJ 1999/3486) y de 23 de mayo de 2000 (RJ 2000/3918). Por otra parte, la STS de 30 de julio de 1998 (RJ 1998/6928) señala la intrascendencia del momento en que se produjo la sucesión en el título a efectos de la aplicación del régimen transitorio diseñado en la CE. Cfr., también, la STS de 17 de septiembre de 2002 (RJ 2002/7813).

33 Señala la STC $1995 \backslash 114$, de 6 de julio que el art. 14 CE reconoce el derecho a no sufrir discriminaciones, pero no el hipotético derecho a imponer o exigir diferencias de trato.

34 En el mismo sentido la STS de 28 de abril de 1989 (RJ 1989/9886). Esta sentencia analizada críticamente por GARCÍA TORRES, J., "Non sint: la Constitución Española y las sucesiones nobiliarias mortis-causa: examen crítico de la argumentación constitucional contenida en la sentencia de la Sala Primera del Tribunal Supremo de 28 de abril de 1989", Revista Española de Derecho Constitucional, op.cit., pág. 266 y ss., en el que señala que el principio de primogenitura es tan discriminatorio como el de masculinidad, pues discrimina "tanto cuando se aplica dentro de la misma línea y grado como cuando determina la línea preamada, e incluso cuando da preferencia en los partos múltiples, y tanto en el orden regular como el irregular". 
masculinidad en igualdad de línea y grado, ha de estimarse discriminatorio y, en consecuencia, abrogado por inconstitucionalidad sobrevenida (art. 14 y Disposición Derogatoria Tercera de la CE ${ }^{35}$. Pero, dado el carácter indivisible de los títulos, es de obligado cumplimiento el "respetar determinados criterios objetivos necesarios que permitan decidir, en cada caso concreto, la persona que ostente el preferente derecho a un título nobiliario ${ }^{36}$.

A pesar de toda esta construcción doctrinal, las decisiones del Tribunal Supremo distan de ser unánimes (GARZÓN, 1993). En algunas sentencias se defienden tesis contradictorias: así, la STS de 18 de abril de 1995 (RJ 1995/3421) $)^{37}$ y en algún voto discrepante en sentencias posteriores, como por ejemplo, en la STS de 13 de febrero de 1996 (RJ 1996/1251) se sostiene que el contenido del Derecho nobiliario no equivale, en ningún caso, a un derecho fundamental ${ }^{38}$.

35 En cuanto a los comentarios respecto la jurisprudencia del Tribunal Supremo, véase: GARCíA TORRES, J., "Non sint: la Constitución Española y las sucesiones nobiliarias mortis-causa: examen crítico de la argumentación constitucional contenida en la sentencia de la Sala Primera del Tribunal Supremo de 28 de abril de 1989", Revista Española de Derecho Constitucional, mayo-agosto, Madrid, 1990, págs. 243-289. Como réplica y crítica a este trabajo, PABÓN DE ACuÑa, J.M, "Comentarios al trabajo "Sint ut fuerunt", de Jesús GARCía TORRES, sobre la Sentencia del Tribunal Constitucional de 3 de julio de 1997", Revista Española de Derecho Constitucional,52, 1998. En sentido análogo, Romero ColOMA, A., "El artículo 14 de la Constitución Española y su relevancia en el ámbito de la sucesión de títulos nobiliarios", Actualidad Administrativa, 47, 1997, págs. 1005-1015. MARTín VIDA, M., "La cuestionable vigencia del principio de masculinidad en la sucesión de títulos nobiliarios (Comentario a la Sentencia del Tribunal Constitucional 126/1997, de 3 de julio)", Revista de Estudios Políticos, Madrid, enero/marzo, 1998, págs. 303-312. Afirma CARreTero SÁnchez, S., en "Títulos nobiliarios. Principio de igualdad y discriminación por sexo. Comentario a la sentencia del Tribunal Constitucional 126/1997, de 3 de julio", La Ley, 1997, 7891, págs. 1.479-1.483, que: "basar una resolución jurídica en un mero estudio de Arqueología Jurídica no parece ser argumento suficiente para el resultado poco acorde para un dictum tan claro como el del art. 14 CE”.

36 La SAP de Sevilla de 15 de junio de 1993 (AC 1993/1251) se expresa a favor de la abrogación del principio de masculinidad del Derecho histórico español en materia de sucesión de títulos de nobleza, y la inconstitucionalidad de la preferencia por razón de sexo.

37 Esta interesante sentencia el Juzgado de Primera Instancia $n^{\circ} .3$ de Madrid estimó la demanda declarando el mejor derecho de la demandante frente al demandado para usar, poseer y disfrutar los títulos de ..., con Grandeza de España y Conde de (...). Se recurrió en apelación y la Sección Octava de la AP de Madrid dictó sentencia revocando la anterior. Se interpuso recurso de casación basándose en que el fallo infringía por inaplicación el art. 14 CE; el recurso fue estimado y sostuvo que "la justificación objetiva y razonable que tan atinadamente ha proclamado el TC para distinguir lo que es discriminatorio de lo que no lo es, resulta patente en el orden del nacimiento (primogenitura) sin que ningún otro añadido o matización por razón de sexo, que sería lo discriminatorio en cuanto que esta última implicaría hoy una distinción de trato injustificada, jurídicamente derogada y socialmente rechazada".

38 En estas fechas era un tema de candente actualidad y prueba de ello son los artículos publicados en prensa que hemos encontrado. En ABC, titulares como: el de 1-9-87: "Se reconoce a la primogénita el derecho a suceder en lo títulos nobiliarios"; LóPEZ VILAS, R., "Ante un nuevo 


\title{
Como conclusión, nuestro Alto Tribunal entiende que la sucesión debe
}

\author{
regirse por el criterio objetivo de primogenitura - porque considera la \\ preferencia de edad como un criterio objetivo, lógico y necesario ${ }^{39}$ - , pero $\sin$ \\ discriminación alguna por razón de sexo (FERNÁNDEZ, 1998).
}

Derecho Nobiliario": 8-11-87; AMORÓs GUARDIOLA, "El problema de la preferencia del varón sobre la mujer en los títulos nobiliarios"; OTERO LASTRES; "La corriente irrefrenable de la historia"; DíAZ DE BUSTAMANTE Y DíAZ, "Nobleza y sucesión” y DE BOB ADILLA, "Precisiones en torno a la no discriminación de la mujer" todos ellos del 9 de noviembre de 1987; el 20-12-88: "Reformas sobre títulos nobiliarios"; el 28-5-89: "El Supremo consolida la doctrina jurisprudencial de igualdad de sexos en la sucesión de los títulos nobiliarios"; 16-4-91: "Títulos nobiliarios: STS de 22 de marzo"; el 13-10-94: "Por primera vez, el Ministerio aplica sentencia favorable a los derechos sucesorios de la mujer"; el 11-6-95: "El TC no revocará la doctrina del TRIBUNAL SUPREMO de que la mujer no sea discriminada en los títulos nobiliarios"; 3-12-96 "Justicia expide los títulos de Conde Villaleal y Duque de Pinohermoso a favor de M.P.S: se hacen así efectivas dos sentencias del TRIBUNAL SUPREMO que crean jurisprudencia en favor de la no discriminación por razón de sexo"; y "El TRIBUNAL SUPREMO anula la cesión de título de Conde de Quintanilla, al vulnerar la primogenitura" y "Nueva sentencia en contra de la preferencia del varón en el orden sucesorio nobiliario"; 13-1-97 "Votos particulares"; 2-7-97: "El TC cierra la polémica sobre títulos nobiliarios y avala la sucesión por el varón"; "Inconstitucionalidad del principio de varonía en la sucesión a los títulos del Reino; Instrucción del fiscal jefe del TSJ de Madrid 3/92, de 28 de octubre de 1992"; 15-12-96: "El Supremo anula la cesión del título de Conde de Quintanilla, al vulnerar la primogenitura"; 11-7-97: "Títulos nobiliarios: críticas al fallo del TC que da preferencia al varón"; 12-10-97: "Un Tribunal da el Marquesado de Nules al varón no primogénito por la doctrina del TC".

39 En relación con el principio de primogenitura, existe una jurisprudencia clara y terminante que considera que la preferencia de edad tiene una justificación objetiva y razonable, ya que parte del carácter indivisible de estas dignidades y del criterio preferencial que otorga al primero en nacer estos derechos nobiliarios. Los argumentos del Tribunal Supremo fueron: en primer lugar, el orden lógico, elemental y necesario para la seguridad jurídica, a modo de criterio preferencial que deriva de la propia naturaleza de las cosas; en segundo término, la expresión del principio o máxima jurídica prior tempore potior iure, que rige y se aplica en numerosos campos del Derecho; y por último, en su carácter objetivo y razonable en cuanto contrario a la institucionalización del desorden y de la inseguridad jurídica, que aparece consagrado y avalado, además, por la propia realidad jurídico-social en numerosas manifestaciones de la vida cotidiana. En este sentido, cfr., en especial, la STS de 28 abril 1989 (RJ 1989/9886), así como las SSTS de 20 de junio (RJ 1987/4540) y de 27 de julio de 1987 (RJ 1987/4540) y (RJ 1987/5877), de 7 de diciembre 1988 (RJ 1988/9324), de 21 diciembre 1989 (RJ 1989/8861), de 3 enero 1990 (RJ 1990/3), de 12 de diciembre de 1990 (RJ 1990/9997) y de 22 marzo 1991, de 18 de abril de 1995 (RJ 3421\1995), de 25 de enero de 1999 (RJ 1999/633), de 19 de febrero de 1999 (RJ 1999/1345) y de 10 de mayo de 1999 (RJ 1999/3342). En ellas se expresa, citándose sentencias del TC de 2 de febrero 1981(RTC 1981/4) y de 18 febrero 1983 (RTC 1983/8), que "la eficacia trascendente del valor de igualdad que consagra el art. $14 \mathrm{CE}$ determina que toda situación de desigualdad, con origen en una circunstancia personal o social que persista, devenga incompatible con el orden de valores que la CE como norma suprema proclama". También aplican este criterio, las SSAP de Madrid de 11 de abril de 1994 (AC 19941869) y de 30 de junio de 1994 (AC 1994/1153). La SAP de Santa Cruz de Tenerife de 4 de octubre de 1994 (AC 1994\1902) declara el mejor derecho genealógico de la hija de la anterior poseedora del título que el nieto de ésta. Con el mismo contenido, la SAP de Madrid de 1 de diciembre de 1992 (AC 1992/1638) y de 3 de mayo de 1995 (AC 1995/1398) y SAP de Barcelona de 14 de junio de 2007 (JUR 2007/18836). 


\section{B. La doctrina del Tribunal Constitucional}

La línea jurisprudencial mantenida por el Tribunal Supremo, contraria a la constitucionalidad del principio de varonía, queda desautorizada a partir de la STC 126/1997, de 3 de julio, que resuelve una cuestión de inconstitucionalidad promovida por la Sección Decimotercera de la Audiencia Provincial de Madrid. Esta cuestión hace referencia al régimen de sucesión de títulos nobiliarios establecido como orden regular de sucesión, dispuesto por el Derecho histórico preconstitucional, al imponer, en los casos de igualdad de línea y grado, la preferencia del varón sobre la mujer. El fallo declara que "el art. 1 de la Ley de 4 de mayo de 1948 y el art. 13 de la Ley de 11 de octubre de 1820, en cuanto declaran aplicable el Derecho histórico y, en particular, la Partida 2. 15. 2., precepto del que deriva la regla de preferencia del varón sobre la mujer en igualdad de línea y grado, en el orden regular de las transmisiones mortis causa de títulos nobiliarios, no es contrario al art. $14 \mathrm{CE}^{\prime 40}$.

El supremo intérprete de la Constitución consideró que el análisis del tema debía hacerse desde "el significado actual de los títulos nobiliarios, considerados como un mero símbolo desprovisto de toda trascendencia jurídico-material”41. De este modo, admitida la constitucionalidad de los títulos nobiliarios por su naturaleza meramente honorífica y la finalidad de mantener vivo el recuerdo histórico al que se debe su otorgamiento, "no cabe entender que un determinado elemento de dicha institución -el régimen de su

40 Es muy interesante el trabajo de Clavero Salvador, B., "Sexo de Derecho, acoso de Justicia: comentario de jurisprudencia", Revista Española de Derecho Constitucional, 52, 1998. págs. 189-217, y su análisis de cuál es realmente la norma que se considera con rango de ley aplicable al caso, de cuya validez dependa el fallo. Esto es, si nos encontramos ante una cuestión de inconstitucionalidad de la jurisprudencia y no de ley, o si por el contrario, estamos ante "una casación en interés de Constitución por encima del Tribunal Supremo". En palabras de este autor, el argumento principal de la sentencia es doble y de apariencia paradójica: "el de la naturaleza inalterable por consistente y la realidad insustancial por simbólica, ambas cosas actuales y así a un tiempo, del título de nobleza". También, vid. CERvilla Garzón, M.D., "La constitucionalidad de la preferencia del varón sobre la mujer en la sucesión nobiliaria (a propósito de la Sentencia del Tribunal Constitucional 126/1997)", Revista General de Derecho, n. 654, 1999, pág. 1766; y RiCOY CASAS, R., "La sucesión de la mujer en los títulos nobiliarios. Especial referencia a la STC 126/97 de 3 de julio de 1997", Anuario de la Facultad de Derecho de Ourense, Vigo, 2004.

41 La STC 126/1997, de 3 de julio, se refiere al principio de masculinidad sólo como "una proyección en esta materia de las ideas sobre la condición de la mujer imperantes en la Edad Media, expresadas en lo jurídico con claridad en otro precepto alfonsino (Partida 4.13.2)".

REVISTA DO DIREITO UNISC, SANTA CRUZ DO SUL

No $39 \mid$ p. 89 - 125| JAN-JUL 2013 
transmisión mortis causa- haya de apartarse de las determinaciones establecidas en la Real Carta de concesión"42.

De este modo, el Tribunal Constitucional declaró vigente el régimen sucesorio de los títulos y proclamó que las dignidades nobiliarias quedaban al margen del texto constitucional y continuaban rigiéndose por sus normas peculiares y exclusivas. En efecto, el Tribunal mantiene que, en materia de títulos nobiliarios, cualquier diferencia de trato que sirva como criterio preferencial, constituye una desigualdad admisible y no una discriminación relevante ${ }^{43}$. Los argumentos que se esgrimen son claros: la ausencia de contenido del título, el minoritario grupo de afectados y la mera existencia de las mercedes nobiliarias ya significa una desigualdad ${ }^{44}$. En la actualidad, la interpretación del contenido jurídico de un título nobiliario, ha quedado reducido al de una merced o dignidad honorífica, a un nomina iuris, que relaciona a quien lo ostenta con una estirpe, con un linaje, en un ámbito de relaciones jurídico-privadas y, por ello, carece de proyección general para considerarla como un status, por lo que no es posible derivar una desigualdad material o una posible discriminación ${ }^{45}$.

En consecuencia, se afirma que el orden regular de sucesión no es inconstitucional, en cuanto que, sus efectos no van más allá de los límites de la

42 "La voluntad regia que ésta expresa no puede alterarse sin desvirtuar el origen y la naturaleza histórica de la institución pues, como ya dijimos, en la mencionada STC 27/1982, de 24 de mayo, resultaría la insalvable contradicción lógica de ser la nobleza causa discriminatoria y, por ende, inconstitucional a la hora de valorar la condición para adquirir el título, pero no a la hora de valorar la existencia misma y la constitucionalidad del título nobiliario en cuestión", STC 126/1997, de 3 de julio. Esto es: no siendo discriminatorio el título de nobleza y, por tanto, inconstitucional, tampoco puede serlo la preferencia masculina en la referida sucesión.

43 Si bien, la STC 9/1983, de 18 de febrero declara que "toda situación de desigualdad persistente a la entrada en vigor de la norma constitucional deviene incompatible con el orden de valores que la Constitución como norma suprema, proclama”.

44 La STC 27/1982, de 24 de mayo señala que "si la nobleza no es en sí discriminatoria, no pueden serlo las condiciones inherentes para adquirirlo. En el hecho de casar con persona noble son de la misma naturaleza el hecho condicionante y condicionado" tan anacrónicos y residuales son ambos, pero no considerado inconstitucional el título, no puede serlo el supeditar su adquisición por vía sucesoria. El hecho de casar con noble no es inconstitucional. Esa condición sería ilícita en cambio "si quisiera vincular el nacimiento o el ejercicio de un derecho público subjetivo".

45 "Un título nobiliario es -y no es más que eso- una preeminencia o prerrogativa de honor, y por eso se entiende nemine discrepante que su concesión corresponde al Rey como uno de esos honores a que se refiere el art. 62 f) CE. Pero en el uso del título (adquirido por sucesión directa o por vía sucesoria) se agota su contenido jurídico, y no es, como en el Antiguo Régimen, signo definitorio de un status o condición jurídica estamental privilegiada, su esencia o consistencia se agota en su existencia”, STC (Sala Segunda) 27/1982, de 24 mayo. 
institución nobiliaria ${ }^{46}$ : se sucede por la voluntad del fundador $y$, supletoriamente por la aplicación de los criterios históricos de primogenitura, masculinidad y representación. En este sentido, se considera conforme a derecho el criterio de preferencia del varón sobre la mujer, abordando la vigencia del principio de masculinidad en el orden regular de transmisión post mortem de los títulos nobiliarios (HERNÁNDEZ-GIL, 1992).

De todo lo anterior, se deduce que, para el Tribunal Constitucional, todos los principios nobiliarios se encuentran vigentes porque son elementos inherentes al propio título de nobleza que se adquiere por vía sucesoria pues, sería "paradójico" contradecir su esencia basándose en principios o criterios diferentes. Esta posible paradoja o contradicción se basaría en que el título sucesorio pudiera adquirirse, no tal como es y ha sido históricamente según los criterios que han presidido las anteriores transmisiones, sino al amparo de criterios distintos ${ }^{47}$. Así, la diferenciación por razón de sexo en la sucesión de dignidades nobiliarias, que sólo poseen en la actualidad el valor de ser un mero honor, no tiene fundamento, ni se encuentra vigente en nuestro Derecho ${ }^{48}$. Por ello, admitida la constitucionalidad de los títulos nobiliarios por su finalidad simplemente honorífica y de mantener vivo el recuerdo histórico al que se debe su otorgamiento, no cabe entender que el régimen de transmisión mortis causa se aparte de las determinaciones establecidas en la Real Carta de concesión.

46 Apunta la SAP de Jaén de 25 de febrero de 1998 que la naturaleza intrínseca de la institución nobiliaria es la desigualdad, sin relevancia constitucional alguna. Por ello, cualquier diferencia de trato para determinar el derecho a poseer esa merced ha de carecer, así mismo, de esa relevancia.

47 Según la STC 1995\114, de 6 de julio.

48 Nos parece interesante destacar las palabras del Tribunal Constitucional cuando explica que "resultaría paradójico que el título de nobleza pudiera adquirirse por vía sucesoria no tal como es y ha sido históricamente según los criterios que han presidido las anteriores transmisiones, sino al amparo de criterios distintos". En especial, se subraya, "no siendo discriminatorio y, por lo tanto inconstitucional el título de nobleza, tampoco puede serlo dicha preferencia (del hombre sobre la mujer) salvo incurrir en una contradicción". Y continúa diciendo que "admitida la constitucionalidad de los títulos nobiliarios por su naturaleza meramente honorífica y la finalidad de mantener vivo el recuerdo histórico al que se debe su otorgamiento, no cabe entender que un determinado elemento de dicha institución -el régimen de su transmisión mortis causa- haya de apartarse de las determinaciones establecidas en la real carta de concesión. La voluntad regia que ésta expresa no puede alterarse sin desvirtuar el origen y la naturaleza histórica de la institución". Por último, en su Fundamento 17, decía: "todo lo expuesto lleva a estimar, en definitiva, que la legislación histórica aplicable a la sucesión regular en los títulos nobiliarios y, en particular, la Partida 2.15.2, de la que deriva la regla o criterio de la preferencia del varón sobre la mujer en igualdad de línea y grado, aplicable en virtud de lo dispuesto en el art. 13 de la Ley 11 octubre 1820 y el art. 1 de la Ley 4 mayo 1948, no es contraria al art. 14 CE". 
La voluntad regia que ésta expresa no puede alterarse sin desvirtuar el origen y naturaleza histórica de la institución.

A pesar de todo, esta decisión no concitó la unanimidad de todos los miembros del Tribunal Constitucional: se suscitaron dos votos particulares manifestados por tres magistrados que entendieron inconstitucional el principio de masculinidad en la sucesión nobiliaria, y advirtieron la necesidad de adaptar la sucesión a la realidad constitucional ${ }^{49}$.

Sea como fuere, lo cierto es que, a partir de la STC 126/1997, el diseño de la doctrina de la derogación del principio de varonía que se estaba consolidando en diversas instancias judiciales se desvanece ${ }^{50}$ y el Tribunal Supremo acoge el principio de la preferencia nobiliaria del varón frente a la mujer en sus STS de 11, 12 y 13 de diciembre de 1997 (RJ 1997/8751) y de 10 de mayo de 1999 (RJ 388/1999).

Cabe añadir que la postura del Tribunal Constitucional se vio también reforzada desde instancias internacionales. Así, el Tribunal Europeo de Derechos Humanos, mediante Decisión de 28 de octubre de 1999, párrafo 6.5, no admitió a trámite la cuestión planteada en relación con la compatibilidad de la regla de varonía con el art. 14 del Convenio Europeo de Derechos Humanos.

49 El voto que suscribieron los magistrados VIVER PI-SUNYER y VIVES ANTÓN sosteniendo que el orden regular de sucesión en los títulos nobiliarios no solamente se encuentra sometido a la Constitución y, más exactamente a las exigencias derivadas del principio de igualdad del art. 14, sino que, al establecer una preferencia del varón sobre la mujer en el orden sucesorio aludido, consagra una discriminación por razón de sexo que vulnera frontalmente una de las prohibiciones a las que, de forma expresa, alude nuestra Norma Fundamental. En dos motivos cuestionan el razonamiento de la sentencia fundamentado en que buena parte de las instituciones existentes antes de 1978 pervivieron con posterioridad, pero no se consideraron inmunes a la Constitución, sino que tuvieron que adaptarse al nuevo orden constitucional, como ejemplo, la institución familiar o del matrimonio. En segundo lugar, respecto al reconocimiento constitucional de los títulos nobiliarios y la desigualdad inherente a ellos, se excluirían las dignidades nobiliarias de las exigencias derivadas del principio de igualdad. Este argumento es criticable pues la Constitución no establece al respecto ninguna inmunidad, a diferencia de lo que ocurre en la sucesión a la Corona al reconocerse expresamente en sede constitucional la preferencia del varón sobre la mujer. Y, por otra parte, el voto particular de CRUZ VILLALÓN quien considera inconstitucional el principio de varonía, por cuanto no se trata de un "elemento basilar "cuya adecuación al principio de igualdad suponga la desnaturalización de la institución nobiliaria, sino de un elemento secundario del sistema, sosteniendo la necesidad de adaptar la institución a las exigencias constitucionales, sin que pueda oponerse la concesión regia de la dignidad ni la consideración de los títulos como simples prerrogativas de honor que ciñen su ámbito de actuación a las relaciones entre particulares.

50 Aunque tenemos que decir que con alguna excepción digna de mención, como la SAP de Navarra de 30 de septiembre de 1999 (AC 1999/8996) que ha seguido admitiendo la tesis de la discriminación. 
Asimismo, el Comité, mediante Decisión de 30 de marzo de 2004, avaló la histórica preferencia del varón en la sucesión nobiliaria, afirmando, con claridad, que el derecho a la igualdad ante la ley reconocido en el art. 26 del Pacto Internacional de Derechos Civiles y Políticos no puede ser invocado como base para reclamar un titulo hereditario de nobleza, ya que la institución nobiliaria, debido a su naturaleza indivisible y excluyente, está al margen de los valores subyacentes a los principios de igualdad ante la ley y no discriminación protegidos en dicho artículo. Finalmente, el Comité estimó que las denuncias presentadas eran incompatibles, rationae materiae, con las disposiciones del Pacto, y en consecuencia, habían de considerarse inadmisibles.

\section{El Consejo de Estado y el principio de varonía}

En este punto, debemos ahora centrarnos en cuál ha sido la opinión del Consejo de Estado, como órgano consultivo, respecto al principio de preferencia del varón en las sucesiones nobiliarias hasta la publicación de la Ley 33/2006.

Desde la perspectiva del Alto Cuerpo Consultivo, el argumento principal que se ha mantenido, desde el Dictamen de 16 julio 1987 (Exp. 50.465/ 50.466), ha sido que el orden regular de sucesión en los títulos de nobleza no infringía el principio de igualdad reconocido en la CE, invocando en su apoyo la doctrina de la STC 27/1982, de 24 mayo. Este criterio que admitía la preferencia de la masculinidad se reiteró en numerosos informes posteriores. Aún así, en ellos se advertía que no se desconocía la nueva orientación que comenzaba a apuntarse en las sentencias del Tribunal Supremo, en aquellos casos donde concurrían hombre y mujer en el mismo grado, en los que se decidió aplicar la preferencia de edad al entender el principio de masculinidad como contrario al artículo $14 \mathrm{CE}$. Pero la guía más segura sobre la interpretación que debía darse al artículo 14 CE, en su aplicación a la materia nobiliaria, era el criterio sentado por la doctrina de la mencionada Sentencia 27/1982 del Tribunal Constitucional ${ }^{51}$.

${ }^{51}$ El Dictamen del Consejo de Estado afirma que "carece de sentido pretender introducir valores constitucionales -y en particular el de igualdad- en el seno de la institución nobiliaria, porque 
En estos momentos, el Consejo de Estado llega a la conclusión de que si se admite la fundamentación constitucional de los títulos nobiliarios, mientras sus efectos no interfieran en otros derechos fundamentales, debe admitirse el orden regular de sucesión vigente. Considera que la institución nobiliaria es ajena a los orígenes ideológicos del mecanismo constitucional y que permanece como un recuerdo histórico en la estructura de nuestra sociedad y cualquier intento de pretender incluir principios constitucionales supondría la desnaturalización de su esencia ${ }^{52}$. Por ello, no cabe sostener que determinadas disposiciones de Derecho nobiliario hayan incurrido en inconstitucionalidad sobrevenida, ya que los títulos nobiliarios no guardan relación alguna con los derechos fundamentales que protege la CE y la Convención de Nueva York ${ }^{53}$.

Entendida la institución nobiliaria como una supervivencia que ha logrado mantenerse por motivos históricos o tradicionales, se considera que es posible su mantenimiento en la actual estructura social, en cuanto resulta ser inocua en su configuración para los valores y exigencias constitucionales. De este modo ha de concluirse, que el orden regular de sucesión en Títulos y Grandezas de España, tal y como aparece regulado en la legislación vigente, no es inconstitucional, ya que, por definición, sus efectos no pueden ir más allá de los límites impuestos a la institución nobiliaria.

En sentido contrario se pronunció el Servicio de Asuntos de Gracia del Ministerio de Justicia en 1987, informando en varios expedientes que "no se puede aceptar la constitucionalidad de los títulos y la inconstitucionalidad del orden sucesorio establecido para aquél"54. Este criterio fue seguido, también, por la Diputación Permanente de la Grandeza.

ello implicaría no sólo la desnaturalización de tal institución, sino sobre todo la de los propios valores constitucionales, que se verían aplicados en un campo ajeno al ethos que los hizo surgir".

52 Sin ánimo de ser exhaustivos, cfr. Dictámenes del Consejo de Estado de 16 de junio de 1987 (50.465/1987), 8 de marzo de 1990 (53587/1990) y 8 de junio de 1990 (54.149/1990). de 27 de noviembre (5677/1997), 21 de noviembre (5676/1997), 23 de diciembre (6067/1997), 27 de noviembre (5680/1997), 27 de noviembre (5679/1997), 21 de enero 1999 (4605/1998), 29 de abril de 2004 (1.727/2000), (652/2004), 24 de febrero de 2005 (235/2005).

53 Dictamen del Consejo de Estado de 17 de enero de 1991 (55.628/1995).

54 Especialmente ilustrativo respecto a las opiniones contrarias a los obiter dicta véase, MARTínEZPereda Rodríguez, J., "La inconstitucionalidad de la preferencia masculina en la sucesión de los títulos nobiliarios", Actualidad Civil, 41, 1991, págs. 545-589. 
IV.- SOBRE LA IGUALDAD DEL HOMBRE Y LA MUJER EN EL ORDEN DE SUCESIÓN DE LOS TÍTULOS NOBILIARIOS: LEY 33/2006, DE 30 DE OCTUBRE.

La Ley $33 / 2006$, de 30 de octubre sobre la igualdad del hombre y la mujer en el orden de sucesión de los títulos nobiliarios ha modificado esencialmente las normas históricas que determinaban los criterios de selección y preferencia aplicables para resolver estos litigios, con una potencial e importante incidencia en el interés deducido en un proceso civil sobre títulos nobiliarios. Su aprobación, rodeada de cierta polémica, ha servido para pacificar la contienda doctrinal $\left.\right|^{55}$ y jurisprudencial sostenida por el Tribunal Supremo y el Tribunal Constitucional, al tiempo que ha adaptado a nuestra realidad una legislación histórica -la de las Partidas-, en buena medida superada.

Una Ley breve que en dos artículos, una disposición transitoria y una cláusula derogatoria genérica, resuelve taxativamente cualquier duda que pueda plantearse respecto a la preferencia del varón sobre la mujer en el orden sucesorio nobiliario, adoptando una clara postura no discriminatoria, pero sin modificar el Derecho nobiliario en su totalidad. En efecto, el objetivo de la Ley es prohibir cualquier preferencia del varón sobre la mujer y, también, la mera exclusión de la mujer de la sucesión nobiliaria.

El Preámbulo de la Ley 33/2006 mantiene que, en la actualidad, la posesión de un título no otorga ningún estatuto de privilegio ya que se trata de

55 En sentido favorable a la tesis que mantiene la discriminación del principio de masculinidad se manifiesta FernáNDEZ Costales, J., "Títulos nobiliarios: derecho sucesorio especial y principios objetivos discriminatorios. Principio de igualdad de sexo y principio de seguridad jurídica". Comentario a la STS de 28 de abril de 1989”, en La Ley, 1989-4, págs. 463 y ss., para quien "injusto y discriminatorio (desigualdad irrazonable) resultaría mantener hoy día la aplicación a una parte del Ordenamiento por los Tribunales de Justicia de un principio selectivo que en modo alguno obedece a la necesidad de su empleo para determinar el orden sucesorio, y que, en definitiva, representaría la forzada subsistencia de un privilegio reservado a los varones de un determinado sector social integrante de la entera comunidad nacional". En sentido casi análogo, Martínez Calcerrada, L., El machismo en el Derecho (Sociología jurídica de la igualdad) Sentencias 18-4-1995 y 6-7-1995 del Tribunal Supremo sobre sucesión de títulos nobiliarios, Granada, 1996, págs. 186-257. En contra de esta opinión, entre otros, ÁlvarEZCienfuegos HeRnándeZ-GiL, A., La preferencia del varón en la sucesión nobiliaria después de la Constitución, Madrid, 1992; Martínez-Pereda RodríGuez, J., "La inconstitucionalidad de la preferencia masculina en la sucesión de los títulos nobiliarios", Actualidad Civil, 41, 1991, págs. 545-589 y LóPEZ GuIZÁn, A., "Títulos nobiliarios y principio de igualdad", Derecho Constitucional para el siglo XXI, Actas del Congreso Iberoamericano de Derecho Constitucional, Tomo I, Madrid, 2003, págs. 865-885.

REVISTA DO DIREITO UNISC, SANTA CRUZ DO SUL

No $39 \mid$ p. 89 - 125| JAN-JUL 2013 
una distinción meramente honorífica cuyo contenido se agota en el derecho a usarlo y protegerlo frente a terceros. A todo ello, hay que añadir la finalidad de mantener vivo el recuerdo histórico de su otorgamiento, razón por la que la sucesión en el título queda vinculada a las personas que pertenecen al linaje del beneficiario de la merced. Este valor puramente simbólico es el que justifica que los títulos nobiliarios perpetuos subsistan en la actual sociedad democrática, regida por el principio de igualdad de todos los ciudadanos ante la ley ${ }^{56}$.

Sin embargo, las normas que regulan la sucesión en los títulos nobiliarios proceden de la época histórica en que la nobleza titulada se consolidó como un estamento social privilegiado, lo que explica que contenga reglas como el principio de masculinidad o preferencia del varón; sin duda, ajustadas a los valores del Antiguo Régimen, pero incompatibles con la sociedad actual en la cual las mujeres participan plenamente en la vida política, económica, cultural y social. Esta plena igualdad del hombre y la mujer en todas las esferas jurídicas y sociales, ya se reconoce en la Convención para la eliminación de todas las formas de discriminación contra la mujer, adoptada en Nueva York el 18 de diciembre de 1979 que fue ratificada por España en 1984.

La Ley señala que el principio de plena igualdad entre hombres y mujeres no debe limitarse al ámbito público sino que debe proyectarse también a "todas las esferas jurídicas y sociales". Incluyendo así, todas las funciones meramente representativas y simbólicas, cuando éstas son reconocidas y amparadas por las leyes. Los sucesivos poseedores de un título de nobleza perpetuo se limitan a mantener vivo el recuerdo de un momento de nuestro pasado histórico. Es más que acertado que la presente Ley reconozca que las mujeres tienen el mismo derecho que los varones a realizar esta función de representar simbólicamente a aquél de sus antepasados que, por sus méritos

56 Afirma García De EnTERRÍA, E., en el Dictamen realizado a petición de la Diputación de la Grandeza sobre la Ley 33/2006, de 5 de enero de 2006, que "la sucesión nobiliaria se venía estructurando en torno a principios como los siguientes: (i) el acto constitutivo de la dignidad nobiliaria sería la ley o título de la sucesión; (ii) la sucesión nobiliaria tendría un único momento de apertura, con la muerte del fundador a quien se le concede el título, y una múltiple delación sucesiva, pasando sucesivamente el derecho al título a cada llamado a la muerte del anterior, según un orden preestablecido desde el acto constitutivo de la dignidad; por lo que (iii) cada nuevo llamado no sería causahabiente de su antecesor, sino que sucedería al fundador, sustituyéndose, sucesivamente, los distintos llamados en el derecho al título". 
excepcionales, mereció ser agraciado por el Rey. El orden de suceder en un título nobiliario queda así configurado respecto a los criterios preferenciales de primogenitura y representación.

En efecto, la Ley reconoce igual derecho a suceder al hombre y a la mujer, sin efectos retroactivos y se aplicará desde su entrada en vigor; con la salvedad, como veremos, de los expedientes abiertos y no resueltos antes del 27 de julio de 2005, que se resolverán conforme a esta nueva regulación ${ }^{57}$.

Así, el art. 1 establece la igualdad de sexos en la sucesión nobiliaria en el orden regular de llamamientos; modificando la legislación y derogando la regla de preferencia del varón sobre la mujer a igualdad de línea y grado. El art. 2 se refiere a la sucesión irregular y dispone "dejarán de surtir efectos jurídicos aquellas previsiones de la Real Carta de concesión del título que excluyan a la mujer de los llamamientos o que prefieran al varón en igualdad de línea y de grado o sólo de grado en ausencia de preferencia de línea o que contradigan de cualquier modo el igual derecho a suceder del hombre y de la mujer".

En efecto, la Ley 33/2006 no permite que las reales cartas de concesión puedan hacer distinciones por razón de sexo en ambos supuestos: la exclusión pura de la mujer, y la preferencia del varón a igualdad de grado en ausencia de preferencia de línea. Ahora bien, "en estos supuestos, los jueces y tribunales integrarán el orden sucesorio propio del título aplicando el orden regular de suceder en las mercedes nobiliarias, en el cual, conforme a lo prevenido por el artículo anterior, no se prefiere a las personas por razón de su sexo"58. En los casos de sucesiones irregulares existentes, las previsiones que diferencian a la mujer frente al varón deberán ser sustituidas por lo establecido en la sucesión regular.

57 Cfr. Gómez De Olea y Bustinza, J., "Mejoras razonables al proyecto de ley de igualdad del hombre y la mujer en el orden de sucesión en los títulos nobiliarios", Boletín de la Real Academia Matritense de Heráldica y Genealogía, Año XVI, 60, Tercer Trimestre, 2006, págs. 17 y ss. LACY, MARQUÉS DE., "De la obsesión al riesgo" Hidalguía, 315, Madrid, 2006, págs.153-163, es una realidad innegable que el título nobiliario tenía una clara función pública que ha perdido en la actualidad. Por el contrario, sostiene GómEZ DE LEÓN LóPEZ, L., "Ante la proposición de Ley en la sucesión de los títulos nobiliarios", Actualidad jurídica Aranzadi, 714/2006, Pamplona, 2006, que este cambio normativo supone dejar a la institución nobiliaria sin sentido y aproximarla a su desaparición.

58 Hemos de llamar la atención sobre la enmienda número 5 del grupo de Coalición Canaria (BOGC, Congreso de los Diputados, de 16 de diciembre de 2005, núms. 198-7, pág.15) al referirse a los dos aspectos contemplados en el art. 2. 
Sin duda, el tema más polémico en esta materia es la aplicación de las normas de Derecho transitorio de la Ley. El problema planteado es el de a quiénes va a afectar el nuevo régimen, es decir, cuáles van a ser los efectos de la retroactividad de la norma.

Así, dispone la Disposición Transitoria Única que:

"En la aplicación de la presente Ley a los títulos nobiliarios concedidos antes de su vigencia se observarán las siguientes normas:

1. Las transmisiones del título ya acaecidas no se reputarán inválidas por el hecho de haberse realizado al amparo de la legislación anterior.

2. Si se pretendiera la rehabilitación de un título nobiliario vacante, se reputarán válidas las transmisiones realizadas conforme a la legislación anterior hasta su último poseedor legal, con respecto del cual y observando las previsiones de esta Ley, habrá de acreditarse la relación de parentesco por quien solicite la rehabilitación.

3. No obstante lo previsto por el apartado 1 de esta disposición transitoria, la presente Ley se aplicará a todos los expedientes relativos a Grandezas de España y títulos nobiliarios que el día 27 de julio de 2005 estuvieran pendientes de resolución administrativa o jurisdiccional, tanto en la instancia como en vía de recurso, así como a los expedientes que se hubieran promovido a partir de aquella fecha, en la cual se presentó la originaria proposición de ley en el Congreso de los Diputados. La autoridad administrativa o jurisdiccional ante quien penda el expediente 0 el proceso concederá de oficio trámite a las partes personadas a fin de que aleguen lo que a su derecho convenga de conformidad con la nueva Ley en el plazo común de cinco días.

4. Quedan exceptuados de lo previsto en el apartado anterior aquellos expedientes en los que hubiera recaído sentencia firme en el momento de la entrada en vigor de la presente Ley".

Pues bien, esta norma en sus apartados primero, tercero y cuarto establece el Derecho transitorio aplicado a toda clase de transmisiones de títulos; y, en el apartado segundo, se establece una norma concreta sobre la rehabilitación. 
Así, en primer lugar, se afirma algo evidente: las transmisiones ya acaecidas se rigen por la legislación anterior y son intangibles; en consecuencia, respecto de las demás transmisiones regirá la Ley 33/2006.

El apartado tercero establece que la nueva ley es aplicable a todos los expedientes relativos a Grandezas de España y Títulos nobiliarios que al día 27 de julio de 2005 estuvieran pendientes de resolución administrativa o jurisdiccional, tanto en la instancia como en vía de recurso ${ }^{59}$. Tras diversos debates parlamentarios se acordó la fecha de 27 de julio de 2005 como el punto de inflexión a partir del cual no se admitirán nuevas decisiones contrarias a la norma constitucional, matizando que la ley se aplicará a todos los expedientes, administrativos y judiciales, en tramitación, a dicha fecha ${ }^{60}$; quedando excluida, por tanto, su aplicación a los ya resueltos (ALCUBILLA, 2006). Esta discutible decisión supone la reconsideración, a la luz de la nueva Ley, de casos ya juzgados aunque sin sentencia firme que para obedecer el nuevo mandato legal han visto radicalmente modificado su sentido ${ }^{61}$. En el apartado cuarto se establece una excepción a todos aquellos expedientes y procedimientos en los que hubiera recaído sentencia firme en el momento de la entrada en vigor de la presente Ley. Y, por último, el apartado segundo hace referencia a la rehabilitación de un título nobiliario vacante, disponiendo que se reputarán válidas las transmisiones realizadas conforme a la legislación anterior hasta su último poseedor legal, con respecto del cual y observando las previsiones de esta Ley, habrá de acreditarse la relación de parentesco por quien solicite la rehabilitación. Por tanto, la Ley 33/2006 se aplicará en el

59 En el expediente que recoge el Dictamen del Consejo de Estado de 3 de julio de 2008 (99973/2008), la cesión, realizada después del 27 de julio de 2005, estaba pendiente de resolución en el momento de entrada en vigor de la Ley 33/2006. Por consiguiente, se aplicó el apartado 3 de la disposición transitoria única no operando la preferencia del varón sino que, en igualdad de grado y línea, ha de regir la regla de primogenitura, con independencia del género.

60 Véase el Diario de Sesiones del Congreso (Comisión de Justicia) de 29 de junio de 2006 (págs. 5739-5742)y el Diario de Sesiones del Senado (Pleno) de 17 de octubre de 2006 (págs. 57845788).

${ }^{61}$ Cervilla Garzón, M.D. "De nuevo sobre la sucesión en los títulos nobiliarios (¿El punto y final a una absurda polémica?), Revista jurídica del Notariado, 59, Madrid, 2006, págs. 214-218, analiza la postura de los que defienden la inconstitucionalidad de la Disposición Transitoria en relación con la prohibición del art. 9.3 CE. Y a favor de una total deslegalización de los títulos nobiliarios Bercovitz Rodríguez-Cano, R., "Les grandeurs de 1'Espagne" Aranzadi Civil, 1, Pamplona, 2007. 
momento que se solicita el expediente de rehabilitación y para quien será su poseedor desde ese momento ${ }^{62}$.

Como hemos señalado, el alcance del apartado 1 de la aludida disposición transitoria es, pues, claro y diáfano, y así lo entendió el Consejo de Estado que consideró que este apartado impide ahora a una mujer alegar ser de mayor edad que el hermano varón que, al fallecimiento del padre común, sucedió en el título en aplicación de la preferencia del varón. Al tratarse de una transmisión del título acaecida, perfeccionada y agotada al amparo de la legislación anterior que daba preferencia al varón, es válida e inatacable, sin ser aplicable la Ley 33/2006 ${ }^{63}$.

El Dictamen del Consejo de Estado de 25 de junio de 2008 (979/2008) ha tenido ocasión de examinar el alcance de la excepción que, respecto a la regla general del apartado 1, supone este apartado 3 en lo que se refiere a un peculiar régimen transitorio, en particular en relación con los expedientes administrativos en curso. Según el Consejo de Estado la nueva ley no se aplicará "a las transmisiones ya acaecidas en las que existiera un poseedor legal que hubiera obtenido la correspondiente resolución administrativa a su favor", pero, por el contrario, será de aplicación "en relación con aquellos títulos que el 27 de julio de 2005 estuvieran pendientes de resolución administrativa"

${ }^{62}$ La Disposición final primera de la Ley contiene una habilitación al Gobierno para su desarrollo, a propuesta del Ministerio de Justicia, de acuerdo con el Consejo de Estado y previa deliberación del Consejo de Ministros. De hecho, en estos momentos se encuentra en trámite de infome por el Consejo de Estado, el Proyecto de Real Decreto por el que se desarrolla la Ley 33/2006, de 30 de octubre, con fecha de 21 de diciembre de 2007. El Preámbulo del Proyecto de Real Decreto señala que la Ley 33/2006 "representa un cambio sustancial en la configuración de la sucesión nobiliaria, que obliga a una aplicación atemperada de los principios tradicionales o históricos, dada la profunda transformación que ha sufrido la institución, y hace aún más necesario poder contar con un conjunto de reglas tendentes al desarrollo de la nueva legalidad para, a través de su interpretación y aplicación, tratar de preservar el sentido y la unidad de la institución nobiliaria y minimizar las incertidumbres que el cambio normativo puede conllevar. El breve, aunque esencial, contenido normativo de la Ley 33/2006, la diversidad de situaciones a las que ha de aplicarse y la dispersión de las normas que rigen la institución nobiliaria, hacen aconsejable ejercitar la habilitación concedida al Gobierno en la disposición final primera de aquélla para desarrollar, a propuesta del Ministerio de Justicia, lo previsto en la presente Ley. Ese desarrollo reglamentario es especialmente necesario allí donde la disposición derogatoria única de la Ley haya alcanzado, aunque sea parcialmente, a la vigente reglamentación en materia de sucesión o rehabilitación nobiliarias.

63 Dictamen del Consejo de Estado de 8 de febrero de 2009 (1.288/2009). En esa misma línea argumental, el dictamen del Consejo 398/2008 consideró válida e inatacable la titularidad y el mejor derecho declarado conforme a la legislación anterior del último poseedor legal, hijo del anterior titular, frente a la pretensión de la hermana de mayor edad del anterior titular. 
(bien por no haber sido dictada ésta o bien por haber sido impugnada en vía judicial), así como en aquellos casos en que el expediente administrativo se hubiera promovido después de aquella fecha, si bien con independencia de que el hecho del fallecimiento del anterior titular se hubiera producido antes 0 después del 27 de julio de 2005. En consecuencia, la disposición se orientaría a dar por buena la posesión efectiva, legal y pacífica existente en la fecha allí mencionada, aplicando la nueva ley en aquellos casos en que, en esa fecha, no existiera esa posesión efectiva, legal y pacífica.

Hemos de advertir, que la Ley 33/2006, para determinar su régimen transitorio, tiene en cuenta la existencia de una investidura formal en los títulos, lo que requiere la tramitación del correspondiente expediente administrativo, no aplicándose por parte de la Administración a aquellos que estuviesen ya resueltos, pero sí a aquellos que estuvieran pendientes de resolución administrativa, solución que -como reitera el Consejo de Estado- ya se adoptó en la anterior modificación del Derecho nobiliario, operada a través del Real Decreto 222/1988, que disponía su aplicación a los expedientes pendientes de resolución ${ }^{64}$.

La regla contenida en la disposición transitoria única de la Ley que considera válidas "las transmisiones del título ya acaecidas (...) al amparo de la legislación anterior", trata de evitar cualquier cuestionamiento de la aplicación de la regla de la preferencia del varón respecto a cualquier poseedor anterior ${ }^{65}$, sin cuestionar ni corregir la aplicación en el pasado del principio de varonía. Las reglas que determinan la aplicación en el tiempo de la Ley 33/2006 consagran su aplicación sólo hacia el futuro, y hacen inatacables las transmisiones habidas desde el fundador hasta el último titular, respetando la

64 El Dictamen del Consejo de Estado de 25 de junio de 2008 (979/2008) afirma que el expediente de sucesión informado fue iniciado después del 27 de julio de 2005, estando, por tanto, sujeto a lo establecido en el apartado 3 de la tantas veces citada disposición transitoria única de la Ley $33 / 2006$, por lo que no es posible aplicar la preferencia del varón, siendo indiferente, por no tener "ius disponiendi" al respecto, la voluntad testamentaria del último titular. Por consiguiente, en igualdad de grado y línea, ha de regir la regla de primogenitura o mayor edad.

65 En este sentido, el Dictamen del Consejo de Estado 398/2008 afirma que la transmisión al último titular después de haberse seguido el correspondiente expediente administrativo, y producida la investidura formal, mediante la expedición de la Real Carta de Sucesión, excluye la aplicación a aquella sucesión de la Ley 33/2006, que no ha tratado de cuestionar ni de corregir problemas sucesorios acaecidos y agotados en el tiempo pasado. En los mismos términos el Dictamen del Consejo de Estado de 14 de julio de 2011 (1118/2011). 
aplicación de la preferencia del varón a las sucesivas delaciones que históricamente se hayan venido produciendo en cada título (Dictamen del Consejo de Estado 2.584/2007). El tenor de dicho apartado 1 en negativo ("no se reputarán inválidas") refleja que la ley no pretende alterar los principios que rigen la institución nobiliaria más allá de la nueva regla de igualdad entre hombres y mujeres introducida en su articulado; de este modo, si existiera un tercero de mejor derecho al amparo de esa legislación anterior, que daba preferencia a la línea masculina, la regla de "sin perjuicio de tercero de mejor derecho" mantendría toda su fuerza ${ }^{66}$.

A propósito de la aplicación del principio de igualdad en la sucesión nobiliaria, la SAP de Madrid de 6 de junio de 2007 (AC 2007/394) declara que al estar esta materia regida por "criterios de política legislativa y, en atención a las circunstancias sociales, al contenido y carácter de los derechos que se encuentran en juego, se pueda y, a veces, se deba, legítimamente conceder efectos retroactivos a las leyes, tal como establece el CC siempre con los límites establecidos por la Constitución en su artículo 9.3 respecto a las disposiciones sancionadoras no favorables o aquellas restrictivas de derechos individuales". Y, tras realizar un análisis de los criterios marcados por el Tribunal Constitucional y por el legislador respecto al contenido y alcance de los derechos nobiliarios, llega a la conclusión de que es difícil defender que con la disposición transitoria de la Ley 33/2006 "se hayan violado derecho individuales, se haya lesionado el derecho a la herencia o nos encontremos ante un supuesto de arbitrariedad porque el legislador haya decido considerar que los expedientes y procesos judiciales que estuviesen en tramitación sobre títulos nobiliarios se verán afectados por la nueva legislación”.

Por otra parte, la SAP de Barcelona de 8 de mayo de 2007 (AC 2007/1718) declara que la aplicación de la Ley 33/2006 altera los Ilamamientos del orden regular de sucesión, pues tras la línea se aplicará la primogenitura, sin distinción de quien proceda sea varón o mujer. Asimismo, tiene en cuenta que la retroactividad de la Ley es de grado medio ${ }^{67}$, esto es, relativa a hechos

66 Vid., Dictamen del Consejo de Estado de 1 de julio de 2011 (1085/2010).

67 Como mantiene la AP de Barcelona, existen excepciones al principio de irretroactividad de las normas jurídicas del art. 2. 3 CC, distinguiendo diversos grados de retroactividad. Así, puede 
anteriores con efectos aún no consumados ni producidos. En el supuesto de hecho, dado que la titular del título había fallecido en 1905 y, cuando se pretende rehabilitar el título y se somete al conocimiento de los órganos jurisdiccionales es en 1981 y en 2000, es indiscutible que el Tribunal debe fallar conforme lo dispuesto en el art. 1 de la Ley 33/2006.

La STS de 3 de abril de 2008 (RJ 251/2008) es clara al afirmar la constitucionalidad de la norma y de su retroactividad porque "si la intangibilidad de los derechos nobiliarios, como nomen iuris o mención honorífica, los convierte en flatus vocis, insustancial e inaprensible para el principio de no discriminación, como es forzoso aceptar a la vista de la jurisprudencia constitucional, la misma levedad de las relaciones jurídicas afectadas conlleva la irrelevancia del mayor o menor alcance temporal de la modificación de su régimen que pueda efectuar el legislador". Y considera que la disposición transitoria es aplicable a los expedientes administrativos sobre títulos nobiliarios, a los recursos contencioso-administrativos contra las resoluciones dictadas por la Administración e, incluso, a los procesos entablados ante el orden jurisdiccional civil, aunque el momento de producirse la vacante del título fuera anterior a la entrada en vigor de la ley ${ }^{68}$.

Por todo ello, no puede pretenderse el amparo del apartado segundo de la DTU de la Ley para eludir la aplicación de su apartado primero, "mediante el mecanismo de interponer una demanda cuyo único objeto es la apertura de un procedimiento judicial cuya causa de pedir con respecto al mejor derecho a poseer un título nobiliario, se ampare exclusivamente en una ley posterior a la concesión administrativa indiscutida del título, ya que de ser así se atentaría al principio de seguridad jurídica con respecto a transmisiones de títulos nobiliarios ya producidas, en que, aun y habiéndose consentido en su día su

hablarse de efecto retroactivo cuando se aplica la nueva Ley a situaciones anteriores ya agotadas, inaplicable en nuestro sistema jurídico, salvo norma en contrario, y el denominado efecto inmediato, es decir, aplicables a situaciones surgidas precedentemente pero que siguen produciendo efectos en la actualidad. La retroactividad puede ser "de grado máximo proscrita en el reseñado precepto, la media (hechos anteriores con efectos no consumados) y la mínima (hechos anteriores con efectos aún no producidos)".

68 En este sentido, la STS, Sala Tercera, de 17 de octubre de 1998 (RJ 1998/ 8841), afirma que la falta de consolidación de la determinación del mejor derecho a ostentar el título que puede predicarse de la pendencia de un expediente administrativo concurre con igual o mayor intensidad cuando la incertidumbre deriva de la pendencia de una demanda civil sobre reclamación del mejor derecho a suceder 
concesión a una persona determinada, ahora se pretenda por la vía judicial y como único argumento, considerar de mejor derecho al primogénito, con lo que se incidiría en una situación de fraude de ley"69.

El Tribunal Constitucional en Auto de 17 de diciembre de 2008 (RTC 389/2008) resuelve la cuestión de inconstitucional planteada respecto al apartado 3 de la disposición transitoria única de la Ley 33/2006, -según la cual, la misma se aplicará a los expedientes que el día 27 de julio de 2005 estuvieran pendientes de resolución-. Considerando que el precepto legal cuestionado es "el resultado de la ponderación efectuada por el legislador entre los valores de seguridad jurídica e igualdad, ambos de relevancia constitucional". EI TC inadmite a trámite la cuestión de inconstitucionalidad planteada por considerarla "notoriamente infundada". Según señala el Auto, esa disposición legal no incide sobre las relaciones consagradas ni afecta a situaciones agotadas y la supeditación de la aplicación de la ley a la pendencia de un procedimiento $o$ de un proceso indica que se está ante un tipo de retroactividad impropia "que incide sobre una situación o relación jurídica, aun no definitivamente establecida, de modo que no existe vulneración del principio de irretroactividad". Si esta doctrina se ha establecido para sucesiones pendientes de resolución, anteriores a la entrada en vigor de la ley, con mucho mayor fundamento ha despejado toda duda de constitucionalidad sobre la aplicación de la Ley 33/2006 a las sucesiones a títulos nobiliarios cuya vacante se haya producido tras su entrada en vigor.

Como hemos señalado, en ese equilibrio entre igualdad y seguridad jurídica, se ha atribuido mayor importancia al principio de igualdad consagrando la equiparación entre $\operatorname{sexos}^{70}$. La igualdad en la sucesión nobiliaria no es contraria a los arts. 9.3 CE -respecto a la irretroactividad de las disposiciones restrictivas de derechos individuales e interdicción de la arbitrariedad de los poderes públicos- y al art. $14 \mathrm{CE}$ sobre la igualdad ${ }^{71}$. A la luz de la doctrina

69 SAP de Madrid (Sección 20a) de 18 febrero (JUR 133/2010) con cita de las SSAP de Lleida (Sección 2a), de 8 enero de 2009 (JUR 188/2008) y Madrid (Sección 10a) de 12 de mayo de 2008 (JUR 314/2007).

70 Dictámenes del Consejo de Estado de 16 de septiembre de 2010 (1811/2010) y de 8 de noviembre de 2010 (2400/2010).

71 El TC sostiene en las SSTC de 22 de julio de 1996 (RTC 1996/134); de 2 de junio de 1998 (RTC 1998/117); de 8 de noviembre de 1999 (RTC 1999/200); de 4 de octubre de 2001 (RTC 2001/ 
constitucional las previsiones de la Ley 33/2006 no inciden sobre relaciones consagradas, ni afecta a situaciones agotadas; antes al contrario, recaen sobre situaciones jurídicas todavía no establecidas definitivamente, no existiendo, por tanto, vulneración del principio de irretroactividad ${ }^{72}$.

En definitiva, y circunscribiéndonos al ámbito jurisdiccional, esta ley señala expresamente su eficacia retroactiva, siendo de aplicación en todos aquellos procesos nobiliarios que se encuentren pendientes en cualquier instancia, a partir de 27 de julio de $2005^{73}$.

Por esa aplicación retroactiva de la Ley 33/2006, se hace preciso determinar cuál es el alcance que puede tener sobre los procesos pendientes en cuestión. Así, en aquellos procesos pendientes en los que se solicita la declaración de mejor derecho a suceder en un título por una mujer, su mejor derecho genealógico se basará en el orden regular en función de los criterios de línea y grado, pues la nueva ley traza un nuevo criterio basado en la igualdad frente al varón poseedor de dicho título. El éxito de su reclamación se producirá de manera inmediata al aplicarse la nueva norma. La reforma en este caso tendrá como efecto el de aportar de manera sobrevenida cobertura jurídica a la pretensión de la mujer demandante (ius superveniens firmat actionem vel exceptionem $)^{74}$.

200); de 15 de febrero de 2007 (RTC 2007/38) que la vulneración del art. 14 CE "la produce sólo aquella desigualdad que introduce una diferencia entre situaciones que pueden considerarse iguales y que carece de una justificación objetiva y razonable, es decir, el principio de igualdad exige que a iguales supuestos de hecho se apliquen iguales consecuencias jurídicas, debiendo considerarse iguales dos supuestos de hecho cuando la utilización o introducción de elementos diferenciadores sea arbitraria o carezca de fundamento racional".

72 El art. 9.3 CE "no permitiría vigencias retroactivas que produzcan resultados restrictivos o limitaciones de los derechos que se habían obtenido en base a una legislación anterior (STC 97/1990, de 24 de mayo, F. 5), aunque, sin embargo, la eficacia y protección del derecho individual nazca de una relación pública o de una privada dependerá de su naturaleza y de su asunción más o menos plena por el sujeto, de su ingreso en el patrimonio del individuo, de manera que la irretroactividad sólo es aplicable a los derechos consolidados, asumidos e integrados en el patrimonio del sujeto y no a los pendientes, futuros, condicionados y expectativas de lo que se deduce que sólo puede afirmarse que una norma es retroactiva, a los efectos del art. 9.3 CE, cuando incide sobre "relaciones consagradas" y afecta a "situaciones agotadas" [por todas, STC 99/1987, de 11 de junio, F. 6 b)]".

73 Vid. STS de 3 de abril de 2008 (RJ 251/2008)

${ }^{74}$ Así sucedió en el que, curiosamente, fue el único litigio en curso a 27 de julio de 2005, a saber: el referente al título del marquesado de Castelldosríus interpuesto por Ágata Ruíz de la Prada frente a su tío. Con anterioridad a la aprobación de la Ley 33/2006, podemos mencionar, como anécdota, el recurso de apelación resuelto en la reciente SAP de Sevilla de 22 de febrero de 2006 (AC 2006/293), en la que, ante la referencia al entonces Proyecto de Ley sobre la igualdad en la sucesión nobiliaria, se indicó que "no puede adelantarse a la realidad acudiendo a proyectos que 
En caso de que, a la inversa, estuviera pendiente algún proceso interpuesto por un varón contra una mujer, en el que éste pretendiera el título por razón de su sexo, la eficacia de la ley tendría el efecto de privarle de forma sobrevenida de interés a su pretensión; efecto que podría alcanzarse a través del art. 22 LEC, lo cual conduciría a una terminación anticipada del proceso.

Con todo, hay sectores de opinión que entienden que el periodo de retroactividad de la ley no es lo suficientemente amplio; algunos argumentan la doctrina de los derechos adquiridos válidamente constituidos y consolidados(LÓPEZ, 2006); otros consideran que es discriminatorio respecto de los casos planteados e inadmitidos, pues entienden que no podrán volver a ser juzgados ${ }^{75}$. En nuestra opinión, sin embargo, puesto que el auto de inadmisión que se dicte no hace referencia al fondo y no tiene por tanto fuerza de cosa juzgada, aquellos procesos que fueron declarados inadmitidos pueden ser ahora replanteados ante los tribunales para ser juzgados bajo la nueva Ley.

Si bien la Ley es clara y, mientras esté en vigor, poco podemos objetar a su aplicación, es evidente que la norma no resuelve todas las dudas que se suscitan en torno a este tema. Opiniones encontradas afirman que eliminar la discriminación que supone la preferencia por el varón no elimina la innegable discriminación que la preferencia por el primogénito consagra con respecto al resto, por no hablar de otras posibles previsiones sucesorias que pudieran contener consecuencias discriminatorias. Argumentar que es un una institución histórica sin mayor trascendencia, no sólo por el reducido número de personas a las que afecta, sino porque no lleva asociados derechos patrimoniales ni económicos, justificaría la admisión de la discriminación en razón del sexo como uno más de los criterios de sucesión de dignidades nobiliarias junto con

están en tramitación parlamentaria y que hasta que no se publiquen en el BOE no son legislación aplicable ni existen en el ordenamiento jurídico". Y, ya estando vigente la reforma legal, ha sido pionera la sentencia del Juzgado de Primera Instancia de Badajoz de 23 de enero de 2007 (AC 2007/224), que estima la demanda sobre mejor derecho a un título nobiliario ejercitada por una mujer contra su hermano en aplicación de la Ley 33/2006.

75 Un tema de gran actualidad que pone de relieve RIVERA DE LA CRUZ, M., "Ser noble en el s. XXI", El País Semanal, 30/9/2007. 
el de primogenitura y línea y grado, al ser particularidades de una institución que su relevante carácter histórico justificaría ${ }^{76}$.

Por otra parte, tampoco se recoge expresamente qué sucedería en la cesión de un título nobiliario (art. 12 del RD de 27 de mayo de 1912) a un varón, hermano menor de una mujer; o los casos de distribución (art. 13 del RD de 27 de mayo de 1912) a varones que son menores que la hermana mayor. Consideramos que sería posible que el varón ostentara la dignidad cedida o distribuida, con la seguridad de que en ambos casos es necesario un cierto control frente a posibles ilícitos o fraudes: por un lado, en el caso de la cesión, la necesidad del consentimiento expreso de la afectada, y en la distribución, la necesidad de aprobación regia ${ }^{77}$.

$\mathrm{Si}$ en esta materia algo nos queda pendiente es, sin duda, el tema referente a la sucesión a la Jefatura del Estado, un asunto que, éste sí, tiene una gran trascendencia por motivos evidentes y para el que no es aplicable la Ley puesto que la norma fundamental otorga de manera inequívoca primacía al varón sobre la mujer (art. $57 \mathrm{CE})^{78}$. Debemos apuntar brevemente que es la CE y no un Derecho histórico el que rige para la sucesión a la Corona. En efecto, el mandato constitucional reconoce la preferencia del varón sobre la mujer y

76 Arévalo Gutiérrez, A., "La mujer en el Derecho nobiliario: la mujer en la sucesión a la Corona", El tratamiento del género en el ordenamiento español: una visión multidisciplinar del tratamiento de la mujer en los distintos ámbitos sociales, Valencia, 2005, págs. 331-385. GIL RoDRíGUEZ DE ClARA, V., "La derogación del principio de varonía en la sucesión del título nobiliario", Estudios de Derecho Judicial, 116, Madrid, 2007, págs. 169-207, considera que la Ley 33/2006, es contraria a la misma naturaleza de los títulos nobiliarios y a las previsiones del art. $62 \mathrm{f}) \mathrm{CE}$.

77 En este mismo sentido, vid. DíEZ-PICAZO Y PONCE DE LEÓn, L., Dictamen emitido a petición de la Diputación de la Grandeza de España, Madrid, 5 de enero de 2005, págs. 24-26. Y, en cuanto a los títulos nobiliarios extranjeros señala que "dista de ser evidente, sin embargo, que la absoluta igualdad entre el hombre y la mujer en la sucesión a los títulos nobiliarios pueda configurarse como un requisito de orden público del Derecho internacional privado español; y ello entre otras razones, porque no son muchos los países que siguen dando reconocimiento oficial a los títulos nobiliarios ni, por consiguiente, los que tienen leyes que adaptar a la igualdad entre hombre y mujer en este campo".

78 Hace ya más de treinta años que se suscitó esta cuestión, así lo afirma ELÍAS DE TEJADA Casanova, J.M., "Comentario sobre la influencia de la reforma de la Constitución en la sucesión de los títulos nobiliarios", La reforma constitucional, Madrid, 2005, págs. 485-498, ya cuando se trató el texto Constitucional en Comisión en el Senado, algunos parlamentarios propusieron eliminar la varonía de la sucesión a la Corona apelando a elementos de modernidad y a lo proscripción de la discriminación sexual. Y en el debate en el Pleno de la Cámara Alta se volvió a plantear esta cuestión sin ningún resultado.

REVISTA DO DIREITO UNISC, SANTA CRUZ DO SUL

No $39 \mid$ p. 89 - 125| JAN-JUL 2013 
modificar esta situación implica una reforma constitucional ${ }^{79}$, un tema de candente actualidad sobre el que tampoco parece que pueda llegarse a un acuerdo $^{80}$.

Nuestro actual sistema político introduce una novedad en el régimen nobiliario, que tiene su fundamento legal en la promulgación del Real Decreto 1368/1987, de 6 de noviembre, sobre Régimen de títulos, tratamientos y honores de la Familia Real y de los Regentes ${ }^{81}$. Esta figura es la de los llamados Títulos de la Casa Real y son los que corresponden a la Corona y al Príncipe heredero, descritos en los arts. 56.2 y $57.2 \mathrm{CE}^{82}$.

Por lo que a nuestro tema interesa, y como ya señaló la STC 126/1997, de 3 de julio, en la actualidad es nítida la distinción entre el orden de sucesión a la Corona y el orden regular de transmisión post mortem de los títulos nobiliarios. El uso de estos títulos dinásticos sólo puede ser autorizados por el titular de la Corona a los miembros de la familia real, con carácter graciable, personal y vitalicio. Esta figura de título de la Casa Real, es nueva en nuestra historia puesto que los miembros de la familia real española nunca han ostentado más título que el propio de Infantes y, cuando ha habido alguna excepción, estos títulos han sido otorgados con sometimiento al mismo régimen jurídico general de los demás títulos nobiliarios.

79 El procedimiento para realizar la reforma con el fin de que no existiera prevalencia del hombre sobre la mujer en la sucesión al trono sería el siguiente: en primer lugar, el Congreso y el Senado deben adoptar, por separado, el principio de reforma y aprobarlo por dos tercios. Al adoptar el principio de reforma, las Cámaras quedan disueltas y se convocan elecciones generales. Una vez constituidas las Cortes, tras las elecciones, éstas deben reiterar el criterio de las Cortes predecesoras, también por una mayoría de dos tercios. Ratificada la decisión se debe redactar la reforma mediante un proyecto de Ley o una proposición de Ley Orgánica y convocar el referéndum nacional. El presidente del Consejo de Estado, RUBIO LLORENTE, considera que esta reforma supone un "problema técnico menor" que nace de la necesidad de acomodar la situación a "la ética contemporánea". Y se baraja la posibilidad de utilizar la figura de un relator. Enuncia algunos puntos a tener en cuenta en la posible reforma constitucional y sostiene como uno de los modelos a seguir el de la Ley de Sucesión al Trono de 27 de marzo de 1953, del Reino de Dinamarca. Vid. Pemán MedinA, P., "La sucesión a la Corona y su repercusión en la sucesión a los títulos nobiliarios", La reforma constitucional, Madrid, 2005, págs. 465-472.

80 Esteban, J. DE., "Igualdad provisional de sexos en la monarquía", El Mundo, 27-09-2006.

81 Para Torre de Silva y López de Letona, J., "Comentario sobre la sucesión en la Corona y su repercusión en la sucesión en los títulos nobiliarios", La reforma constitucional, Madrid, 2005, págs. 473-484, existe una divergencia evidente entre los caminos de la sucesión en los títulos nobiliarios y la sucesión en la Corona a partir del constitucionalismo del siglo XIX y se distanciaron definitivamente tras la Constitución.

82 Vid., De Prada Rodríguez, M., La tutela sustantiva y procesal de los títulos nobiliarios, págs. 219-220. 
Cfr. VallterRa FernÁndez, L., "La sucesión nobiliaria a debate. (Crónicas de unas sentencias. ¿Históricas o Histriónicas?), en Hidalguía, Madrid, 1998.

Vid. Álvarez-Cienfuegos Hernández-GiL, A., La preferencia del varón en la sucesión nobiliaria después de la Constitución, Madrid, 1992

Vid. Arnaldo Alcubilla, E., "Régimen Transitorio de la Ley 33/2006, de 30 de octubre, sobre igualdad del hombre y la mujer en el orden de sucesión de los títulos nobiliarios", La Ley, 6749, Madrid, 2006.

GÓMEZ DE LEÓN LÓPEZ, L., "Ante la proposición de Ley en la sucesión de los títulos nobiliarios", Actualidad jurídica Aranzadi, 714/2006, Pamplona, 2006, pág. 3.

Vid., De Prada Rodríguez, M., La tutela sustantiva y procesal de los títulos nobiliarios, págs. 219-220. ACHAR ANO

ENTRENA CUESTA, R., Comentarios a la Constitución, Madrid, 2001, pág. 39.

Professor Convidado 